\section{OPEN ACCESS}

Edited by:

Elvira Galieva,

Novosibirsk State University, Russia

Reviewed by: Cesar Fortes-Lima,

Uppsala University, Sweden

Francesca Lantieri,

University of Genoa, Italy

${ }^{*}$ Correspondence:

Julio Granados

julgrate@yahoo.com

orcid.org/0000-0001-8553-1027

Specialty section:

This article was submitted to Evolutionary and Population Genetics, a section of the journal

Frontiers in Genetics

Received: 27 April 2021

Accepted: 12 July 2021

Published: 03 August 2021

Citation:

Hernández-Doño S,

Jakez-Ocampo J, Márquez-García JE,

Ruiz D, Acuña-Alonzo V, Lima G,

Llorente L, Tovar-Méndez VH,

García-Silva R, Granados J, Zúniga J and Vargas-Alarcón G (2021)

Heterogeneity of Genetic Admixture

Determines SLE Susceptibility

in Mexican. Front. Genet. 12:701373.

doi: 10.3389/fgene.2021.701373

\title{
Heterogeneity of Genetic Admixture Determines SLE Susceptibility in Mexican
}

\begin{abstract}
Susana Hernández-Doño, Juan Jakez-Ocampo², José Eduardo Márquez-García ${ }^{3}$, Daniela Ruiz", Víctor Acuña-Alonzo ${ }^{5}$, Guadalupe Lima², Luis Llorente'2, Víctor Hugo Tovar-Méndez ${ }^{6}$, Rafael García-Silva7, Julio Granados ${ }^{1 *}$, Joaquín Zúñiga ${ }^{8,9}$ and Gilberto Vargas-Alarcón ${ }^{10}$
\end{abstract}

\begin{abstract}
1 Immunogenetics Division, Department of Transplant, Instituto Nacional de Ciencias Médicas y Nutrición Salvador Zubirán, Mexico City, Mexico, ${ }^{2}$ Department of Immunology and Rheumatology, Instituto Nacional de Ciencias Médicas y Nutrición Salvador Zubirán, Mexico City, Mexico, ${ }^{3}$ Molecular Biology Core Facility, Instituto Nacional de Enfermedades Respiratorias Ismael Cosío Villegas, Mexico City, Mexico, ${ }^{4}$ Department of Dermatology, Hospital General Dr. Manuel Gea González, Mexico City, Mexico, ${ }^{5}$ Laboratory of Physiology, Biochemistry, and Genetics, Escuela Nacional de Antropología e Historia, Mexico City, Mexico, ${ }^{6}$ Department of Endocrinology, Instituto Nacional de Ciencias Médicas y Nutrición Salvador Zubirán, Mexico City, Mexico, ${ }^{7}$ Department of Internal Medicine, Instituto Nacional de Ciencias Médicas y Nutrición Salvador Zubirán, Mexico City, Mexico, ${ }^{8}$ Laboratory of Immunobiology and Genetics, Instituto Nacional de Enfermedades Respiratorias Ismael Cosío Villegas, Mexico City, Mexico, ${ }^{9}$ Tecnologico de Monterrey, Escuela de Medicina y Ciencias de la Salud, Mexico City, Mexico, ${ }^{10}$ Research Direction, Instituto Nacional de Cardiología Ignacio Chavez, Mexico City, Mexico
\end{abstract}

Systemic Lupus Erythematosus (SLE) is an autoimmune inflammatory disorder for which Major Histocompatibility Complex (MHC) genes are well identified as risk factors. SLE patients present different clinical phenotypes, which are partly explained by admixture patterns variation among Mexicans. Population genetic has insight into the high genetic variability of Mexicans, mainly described through HLA gene studies with anthropological and biomedical importance. A prospective, case-control study was performed. In this study, we recruited 146 SLE patients, and 234 healthy individuals were included as a control group; both groups were admixed Mexicans from Mexico City. The HLA typing methods were based on Next Generation Sequencing and Sequence-Based Typing (SBT). The data analysis was performed with population genetic programs and statistical packages. The admixture estimations based on HLA$\mathrm{B}$ and -DRB1 revealed that SLE patients have a higher Southwestern European ancestry proportion $(48 \pm 8 \%$ ) than healthy individuals (30 $\pm 7 \%)$. In contrast, Mexican Native American components are diminished in SLE patients (44 $\pm 1 \%$ ) and augmented in Healthy individuals (63 $\pm 4 \%$ ). HLA alleles and haplotypes' frequency analysis found variants previously described in SLE patients from Mexico City. Moreover, a conserved extended haplotype that confers risk to develop SLE was found, the HLA-A*29:02 C*16:01 B*44:03 DRB1*07:01 DQB1*02:02, $p C=0.02$, $\mathrm{OR}=1.41$. Consistent with the admixture estimations, the origin of all risk alleles and haplotypes found in this study are European, while the protection alleles are Mexican Native American. The analysis of genetic distances supported that the SLE patient 
group is closer to the Southwestern European parental populace and farthest from Mexican Native Americans than healthy individuals. Heterogeneity of genetic admixture determines SLE susceptibility and protection in Mexicans. HLA sequencing is helpful to determine susceptibility alleles and haplotypes restricted to some populations.

Keywords: HLA, Mexican, population genetics, heterogeneity, HLA-DRB1*03:01, admixture, conserved extended haplotype

\section{INTRODUCTION}

Systemic Lupus Erythematosus (SLE) is a chronic autoimmune disease characterized by the loss of tolerance to self-antigens and interferon responses dysregulation. SLE manifestations are diverse; the condition can affect almost any organ in the body (Ghodke-Puranik and Niewold, 2015). Patients with Hispanic, African, and Asian ancestry develop SLE earlier than European populations. These patients also have more acute disease onset, more severe clinical manifestations, higher disease activity, chronic organ damage, and higher mortality (Carter et al., 2016). Hispanic SLE prevalence is $\sim 138 / 100000$ per inhabitants per year, which is higher than in Asian and European populations (AtishaFregoso et al., 2011). Many differences in the disease presentation across the ethnic barrier have been explained throughout genetic predisposition. One of the most studied systems is the Major Histocompatibility Complex (MHC) class I and class II genes, known as Human Leukocyte Antigen (HLA) Class I and II. The HLA variability among populations is helpful to explain many characteristics of SLE (Tsokos et al., 2016), and it continues to give more information about the genetic predisposition and pathophysiological mechanism of the disease.

As mentioned before, HLA haplotypes confer susceptibility or protection in an ethnic-dependent manner (Vargas-Alarcón et al., 2001; Vasconcelos et al., 2009; Furukawa et al., 2014; Alarcón-Riquelme et al., 2016; Molineros et al., 2019). In Mexico, susceptibility varies as the ethnic admixture does, the admixture in Mexico is very heterogeneous across the Country, contributing to the disease variability (Moreno-Estrada et al., 2014; Barquera et al., 2020b). Therefore, the admixture diversity has contributed to the enrichment of susceptibility markers and an ample SLE phenotypes specter in Mexicans (Salgado-Galicia et al., 2020). For instance, the most common susceptibility allele, HLA-DRB1*03:01, previously identified in Mexico City, was not found in Tapachula Chiapas SLE patients. Otherwise, HLA-DR2 Chiapas patients showed a higher risk of developing SLE once infected with Zika or Chikungunya viruses common in that region but absent in Mexico City (Sepúlveda Delgado et al., 2018). Besides, population genetic studies revealed significantly different admixture estimates for Mexico City and Tapachula, Chiapas (Barquera et al., 2020e).

Equally important, conserved extended haplotypes (CEHs) help to defined susceptibility, and the alleles help MHC genetic diversity measurements in autoimmune conditions. CEHs are DNA blocks defined as combinations of HLA-B, $\mathrm{DR}$, complement, and other immune-related genes. CEHs are known as DNA stretches with fixed alleles, including those at loci not tested (Wescott et al., 1987). Thus, CEHs have a high genetic load, so determining HLA CEHs gives information about the aggregated risk confer by non-classical and non-HLA genes linked to HLA. The frequency and allele combination of CEHs varies between major ethnic groups. Hence, the determination of $\mathrm{CEH}$ and the ethnic admixture print allows knowing immunogenetic variants and blocks of anthropological origin and evolution but biomedical importance in Mexican mestizo patients.

Thus, this study aimed to describe SLE patients' ethnic admixture proportions compared with healthy Mexican Mestizo individuals. We searched the distribution of HLA class I and class II blocks and $\mathrm{CEH}$ and their most likely ancestral origins using high-resolution HLA typing in a Mexican SLE group of admixed-ancestry.

\section{SUBJECTS, MATERIALS, AND METHODS}

\section{Subjects}

We recruited 146 consecutive SLE patients between 2015 and 2018 from the Rheumatology Outpatient Clinic at the Instituto Nacional de Ciencias Médicas y Nutrición Salvador Zubirán (INCMNSZ) in Mexico City. As a control group, 234 unrelated healthy Mexican admixed individuals were included. Eligible SLE patients included those born in Mexico, whose parents and grandparents were also born in Mexico. Specifically, those who were born in Mexico City and its borders. The same criterion was applied for controls.

The general health status was evaluated or investigated for both SLE and controls. The SLE patients' diagnosis and classification were based on clinical manifestations, laboratory tests, and the American College of Rheumatology (ACR) criteria (Hochberg, 1997). The general health status in SLE patients was assessed with the SLE Activity Index (SLEDAI) (Bombardier et al., 1992; Guzmán et al., 1992). The patients were classified with punctuations between 0 and 4 it means inactive disease state or mild activity. The SLE classification punctuation was a criterion to establish the activity of the disease at the time of the interview.

Additionally, Systemic Lupus International Collaborating Clinics/American College of Rheumatology (SLICC/ACR) Damage Index (SDI) (Gladman et al., 2000) was registered for patients. This index was considered part of the health status evaluations, and it was thought as applicable to associate chronic evolution to genetic predisposition. The patients' quality of life was also evaluated with the questionnaire Lupus Quality of Life (Lupus Qol), ranging in punctuations from 0 to 100 
(Devilliers et al., 2012). Additionally, it was verified that all patients were consecutive in their medical controls and complete compliance with pharmacological treatment. All the above, to rule out that a severe phenotype, evolution at the study moment, or chronic damage was due to lack of accessibility to medical service, lack of patient adherence, additional stresses concerning the quality of life, and more likely associated with an immunogenetic predisposition.

In controls, the general state of health was recorded as self-perceived health and ruling out autoimmune, metabolic, cancer, or any repetitive disease or chronically treated. To establish the similarity in the exposure to possible triggers of the disease, both control individuals and patients belong to the same geographical area, which is expressed as latitude and longitude in the sociodemographic information Table 1.

Finally, the socioeconomic status was verified. The social worker's department verified the patients' socioeconomic strata using a validated instrument applied to all the institutions belonging to the Coordinating Commission of National Institutes and High Specialty Regional Hospitals (CCIHSHAE). This instrument includes variables with a numerical value to assign the socioeconomic level: monthly family income, occupation of the primary economic provider, monthly family expenses, housing, and family health status. The sum of variables gives an approximation of the socioeconomic level.

\section{Human Leukocyte Antigen Typing Sanger Sequencing-Based Typing}

Genomic DNA was obtained from whole blood using the QIAamp DNA mini kit (Qiagen, Valencia, CA, United States). DNA quality was assessed using a NanoDrop 2000 (Thermo Fisher Scientific, MA, United States) and Qubit Fluorometric Quantification (Invitrogen). The DNA integrity was evaluated by gel electrophoresis. Samples were stored at $-20^{\circ} \mathrm{C}$ until analysis. The HLA typing was performed using a sequence-based method (SBM) described previously (Zúñiga et al., 2013).

Briefly, HLA class I typing was done by generic amplification of exons 2, 3, and 4 of each gene. For HLA class II, exon 2 and 3 of the HLA-DRB1 and -DQB1 genes were amplified using allele group-specific primer pairs. Polymerase chain reactions (PCRs) utilized $1.5 \mathrm{~mm} \mathrm{KCl}, 1.5 \mathrm{mM} \mathrm{MgCl} 2,10 \mathrm{mM}$ Tris$\mathrm{HCl}$ ( $\mathrm{pH} 8.3$ ), $200 \mathrm{mM}$ dNTPs, $10 \mathrm{pM}$ of each primer, $30 \mathrm{ng}$ of DNA, and $0.5 \mathrm{U}$ of Taq DNA polymerase in a final volume of $25 \mu \mathrm{l}$. Amplifications were performed on a PE9700 thermal cycler (Applied Biosystems, Foster City, CA, United States) under the following cycling conditions: $95^{\circ} \mathrm{C}$ for $30 \mathrm{~s}, 65^{\circ} \mathrm{C}$ for $30 \mathrm{~s}$, $72^{\circ} \mathrm{C}$ for $1 \mathrm{~min}$, preceded by $5 \mathrm{~min}$ at $95^{\circ} \mathrm{C}$ and followed by a final elongation step at $72^{\circ} \mathrm{C}$ for $5 \mathrm{~min}$. The amplified products were sequenced independently in both directions using BigDye ${ }^{\circledR}$ Terminator v3.1 Cycle Sequencing Kit (Applied Biosystems $^{\text {TM }}$ ) on the ABI PRISM ${ }^{\circledR} 3500$ Genetic Analyzer (Applied Biosystems ${ }^{\circledR}$ ). Sequencing products were purified with the BigDye XTerminator ${ }^{\circledR}$ Purification Kit (Applied Biosystems) to remove unincorporated BigDye ${ }^{\mathrm{TM}}$ terminators and salts.

We analyzed data with matching allele assignment software (Applied Biosystems) using the IMGT/HLA sequence database alignment tool http://www.ebi.ac.uk/imgt/hla/align.html (Robinson, 2001). We solved ambiguities using group-specific sequencing primers (GSSPs) that had been previously validated (Lebedeva et al., 2011).

\section{High-Resolution Typing by Next-Generation Sequencing}

Next-generation sequencing Illumina ${ }^{\circledR}$ TruSight $^{\circledR}$ HLA v2 Sequencing Panel (Illumina, San Diego, CA, United States) was also used to confirm HLA allele-level typing. We performed the process as the manufacturer recommends. Briefly, genomic DNA samples were adjusted to a working concentration of $10 \mathrm{ng} / \mu \mathrm{L}$ using Qubit equipment (Thermo Fisher Scientific, Waltham, MA, United States).

TABLE 1 | Clinical and sociodemographic information from SLE patients and controls.

\begin{tabular}{|c|c|c|}
\hline Variable & SLE & Controls \\
\hline $\begin{array}{l}\text { Diagnosis Age, years, } \\
\text { Mean } \pm S D\end{array}$ & $24.5 \pm 11.2$ & - \\
\hline Age, years, Mean $\pm S D$ & $39.7 \pm 14.5$ & $38 \pm 15.3$ \\
\hline Female & 104 (89\%) & $120(51 \%)$ \\
\hline Male & $13(11 \%)$ & 114 (49\%) \\
\hline Family & $\begin{array}{l}\text { Grandparents and } \\
\text { parents born at the same } \\
\text { location }\end{array}$ & $\begin{array}{l}\text { Grandparents and } \\
\text { parents born at the same } \\
\text { location }\end{array}$ \\
\hline Latitude (Living locality) & $19^{\circ} 25^{\prime} \mathrm{N}$ & $19^{\circ} 26^{\prime} \mathrm{N}$ \\
\hline Longitude (Living locality) & $99^{\circ} 7^{\prime} \mathrm{W}$ & $99^{\circ} 8^{\prime} \mathrm{W}$ \\
\hline Urban/rural (Living locality) & Urban & Urban \\
\hline Socioeconomic status & Low to middle & Low to middle \\
\hline \multicolumn{3}{|l|}{ Health status } \\
\hline $\begin{array}{l}\text { Chronic diseases } \\
\text { (Diabetes, hypertension) }\end{array}$ & $6 \%$ & $0 \%$ \\
\hline $\begin{array}{l}\text { SLEDAI \% of individuals } \\
\text { (score) }\end{array}$ & $\begin{array}{l}64 \% \text { Inactive disease } \\
(0-2) 36 \% \text { mild activity } \\
(3-4)\end{array}$ & NA \\
\hline SDI \% of individuals (score) & $\begin{array}{l}84.6 \%(0-1) 13.67 \% \\
(2-4) 1.73 \%(5-8)\end{array}$ & NA \\
\hline LupusQol \% of individuals & $68 \%(>60)$ & NA \\
\hline
\end{tabular}

(score)

Lupus phenotype and clinical manifestations Articular $\quad 79.8 \%$

Serositis $\quad 29.7 \%$

Renal $\quad 65.6 \%$

Neurologic $\quad 16.4 \%$

Hematologic $\quad 64.8 \%$

Antiphospholipid syndrome $\quad 30.4 \%$

Other autoimmune $\quad 34.5 \%$

diseases

ANAs $\quad 86 \%$

Relatives' information

Relative with SLE $\quad 18.6 \%$

Relative with autoimmune $\quad 29.4 \%$

disease

NA, not applicable; SLEDAI, SLE disease activity index; SDI, Systemic Lupus International Collaborating Clinics/American College of Rheumatology (SLICC/ACR) Damage Index; ANAs, antinuclear antibodies. 
Generation of Long-range PCR templates. HLA-A,-B,-C,DRB1, and -DQB1 loci were prepared using specific primers included in the TruSight HLA Pre 24 sample kit (Illumina) and MasterAmpTM Extra-Long DNA Polymerase (Lucien Corporation, Middleton, WI, United States).

Polymerase chain reactions were performed in a 96-well plate on the $9700 \mathrm{PE}$ thermal cycler (Applied Biosystems/Thermo Fisher Scientific) using the following reagents proportions: $25 \mu \mathrm{l}$ of HPM (HLA-PCR Mix), $2 \mu \mathrm{l}$ of MasterAmpTM ExtraLong DNA Polymerase, $13 \mu \mathrm{l}$ of water, and $5 \mu \mathrm{l}$ of gDNA (10 ng/ $\mu \mathrm{l})$. Two PCR programs were performed for the fragment amplification of HLA loci. The first one for amplification of HLA$\mathrm{A},-\mathrm{B},-\mathrm{C}$, and -DRB1 loci, under the following conditions: initial denaturation at $94^{\circ} \mathrm{C}$ for $3 \mathrm{~min}, 30$ cycles at $94^{\circ} \mathrm{C}$ for $30 \mathrm{~s}, 60^{\circ} \mathrm{C}$ for $2 \mathrm{~min}, 68^{\circ} \mathrm{C}$ for $15 \mathrm{~min}, 68^{\circ} \mathrm{C}$ for $10 \mathrm{~min}$, and a final hold at $10^{\circ} \mathrm{C}$.

The second PCR program for locus HLA-DQB1 was performed under the following conditions: $94^{\circ} \mathrm{C}$ for $3 \mathrm{~min}$; followed by 10 cycles at $94^{\circ} \mathrm{C}$ for $30 \mathrm{~s}, 55^{\circ} \mathrm{C}$ for $\min , 72^{\circ} \mathrm{C}$ for $15 \mathrm{~min} ; 20$ cycles of $94^{\circ} \mathrm{C}$ for $30 \mathrm{~s}, 60^{\circ} \mathrm{C}$ for $2 \mathrm{~min}, 72^{\circ} \mathrm{C}$ for $15 \mathrm{~min}, 72^{\circ} \mathrm{C}$ for $10 \mathrm{~min}$; and a final hold at $10^{\circ} \mathrm{C}$. PCR products were confirmed by $1 \%$ agarose gel electrophoresis. The PCR clean-up was performed too.

Normalization and tagmentation. All loci PCR products' concentrations were normalized using magnetic beads (LNA1, LNB1, TruSight HLA, Illumina). This process is accomplished for multiplex library preparation and sequencing. After normalization, $40 \mu \mathrm{l}$ of each PCR product was used for fragmentation (800 and $1200 \mathrm{pb}$ ), and fragmentation buffers HTM and HTB (TruSight HLA Pre-PCR 24, Illumina) were added to the reaction $\left(10 \mu \mathrm{l}\right.$ each) and incubated at $58^{\circ} \mathrm{C}$ for $12 \mathrm{~min}$ in the presence of sequencing primers. The purified fragmented PCR products were pooled, and adaptor addition was performed using the Nextera XT DNA sample preparation kit (Illumina). Amplification was performed based on the following PCR program: denaturation at $72^{\circ} \mathrm{C}$ for $3 \mathrm{~min}$ and $98^{\circ} \mathrm{C}$ for $30 \mathrm{~s}$, followed by 10 cycles at $98^{\circ} \mathrm{C}$ for $10 \mathrm{~s}, 60^{\circ} \mathrm{C}$ for $30 \mathrm{~s}, 72^{\circ} \mathrm{C}$ for $5 \mathrm{~min}$, and a final hold at $10^{\circ} \mathrm{C}$. Appropriate clean-up was performed.

Sequencing. Seven microliters of the PCR sequencing products were denatured with $10 \mu \mathrm{l}$ of $0.1 \mathrm{~N} \mathrm{NaOH}$ and sequenced on a MiSeq instrument using the paired-end 300 cycle $(2 \times 150$ bp paired-end) MiSeq Reagent Kit (Illumina) following the manufacturer instructions.

\section{Next-Generation Sequencing Data Analysis}

After the sequencing, MiSeq reporter analysis software-generated FASTQ sequence files and BAM alignment files. Next, we generated allele calls using the Assign 2.0 $0^{\mathrm{TM}}$ TruSight HLA Analysis software. The software used reference sequences from the IMGT/ HLA database (release 3.23.0.0).

\section{Statistical Analysis}

\section{Clinical and Sociodemographic Characteristics}

We analyzed clinical and demographic variables with the IBM SPSS Statistics 26 program.

\section{Human Leukocyte Antigen Class I and Class II Alleles and CEH Frequencies}

Differences in HLA class I and II alleles and haplotypes frequencies between patients and controls were analyzed using $\mathrm{X} 2$, and $p$-Values less than 0.05 were considered statistically different. $P$-values were also corrected using the Bonferroni method (for allele frequencies, multiplying the original $p$-Value by the number of alleles). Odds ratios (OR) and 95\% confidence intervals $(95 \% \mathrm{CI})$ were calculated to measure association strength with the program Epi Info ${ }^{\mathrm{TM}} 7.2$ version (Centers for Disease Control and Prevention, 2011). We generated a Forest plot of HLA alleles and haplotypes, which showed statistical significance using R programming version 4.0.3 (R Core Team, 2020).

Hardy-Weinberg equilibrium (HWE) at a locus-by-locus level was calculated. HLA alleles data was faced with the hypothesis that the observed diploid genotypes are the product of a random union of gametes. To detect significant departure from HWE was followed an analogous Fisher's exact test on a two-by-two contingency table but extended to a triangular contingency table of arbitrary size. The test was done using a modified version of the Markov-chain with the populations' genetic computer program Arlequin version 3.5.2.2 (Guo and Thompson, 1992; Excoffier and Lischer, 2010).

Furthermore, we calculated the diversity values: observed heterozygosity $(\mathrm{OH})$, expected heterozygosity $(\mathrm{EH})$, and the polymorphic information content (PIC) for each locus (HLAA, -C, -B, -DRB1, and -DQB1). CEH of known Mexican Native American, European, African, and Asian origin were assigned based on previously reported frequencies investigated as Most Probably Ancestry (MPA) in previous studies. MPA is based on the frequency occurrence of haplotypes (Cao et al., 2001; Yunis et al., 2003, 2005; Zúñiga et al., 2013). Individual alleles and haplotypes frequencies and locality of occurrence searching HLA tool can be found in Allele Frequency Net Database, the gold-standard data classification (Gonzalez-Galarza et al., 2020).

Linkage disequilibrium (LD) between HLA loci pairs was calculated based on delta $(\Delta)$, a LD coefficient, which measures the deviation from a random association between alleles of different loci. The results have been reported as relative delta $\left(\Delta^{\prime}\right)$ values. $\Delta^{\prime}$ oscillates among values from -1 to 1.1 represents the highest probability that a pair of alleles or DNA segments segregates as a block. In contrast, -1 represents the probability of a total random pairing (Excoffier and Lischer, 2010).

\section{Admixture Estimation}

The maximum likelihood method was used to estimate SLE patients' and healthy individuals' admixture proportions using the population genetics LEADMIX software (Wang, 2003). Four major parental populations $(k=4)$ were evaluated, including a population per continental location according to the settlement history in Mexico. According to the availability of HLA data, the populations included were Mexican Native American, Southwestern European, Sub Saharan African, and Eastern Asian. HLA-B and -DRB1 were used as genetic estimators in the included populations. We estimated Mexican Native 
American contribution from Oaxaca Mixtecs data, a populace from southeastern Mexico (Arnaiz-Villena et al., 2014), and Chihuahua Tarahumaras, a northern Mexico population (GarcíaOrtiz et al., 2006). Similarly, we estimated non-autochthonous parental populations' contribution with data obtained from Southwestern European components from a representative sample from Spain (Catalunya, Navarra, Extremadura, Aragon, and Cantabria) (Enrich et al., 2019), Sub-Saharan African components from Zimbabwe Harare Shona Inhabitants (Louie, 2006b), and Eastern Asian components from the China Han populace (Trachtenberg et al., 2007).

\section{Genetic Distance and Principal Component Analysis}

Genetic distances were assessed for the parental populations evaluated in the admixture estimation $(k=4)$ (Mexican Native American, Southwestern European, Sub-Saharan African, and Eastern Asian). This analysis was based on HLA-B. Besides, we included other Mexican Native American groups to deepen the comparison; the groups added were: Lacandon Mayans (Barquera et al., 2020f), Oaxaca Mixe (Hollenbach et al., 2001; Single et al., 2020), Oaxaca Zapotecans (Hollenbach et al., 2001), and Seri (Gorodezky, 2006). The genetic distance analysis included Nei's distance performed with the Arlequin genetics population program. We generated graphics with an $\mathrm{R}$ programming extension added to Arlequin.

Principal Components Analysis (PCA) for fifty-six populations with HLA-B data available was performed using the BioVinci Software 2.0 to analyze the distribution of HLA-B alleles. There were included populations from three continental locations European, African, and Latin-American. The study groups SLE and controls HLA-B were adjusted to low-resolution. PCA included population data of African populations (7 populations): Burkina Faso Mossi (Modiano et al., 2001), Cameroon Yaounde (Pimtanothai et al., 2001), Ghana Ga-Adangbe (Norman et al., 2013), Kenya (Mack et al., 2006), Kenya Nandi (Cao et al., 2004), Uganda Kampala (Kijak et al., 2009), and Zimbabwe Harare Shona (Louie, 2006a). European populations (8 populations): England*, France Lyon*, Germany Essen*, Ireland Northern (Williams et al., 1999; Middleton et al., 2000), Italy*, Italy Sardinia (Grimaldi et al., 2001), Netherlands* and Spain (Enrich et al., 2019). Mexican Mestizo populations from Northern Mexico (7 populations): Baja California (Escobedo-Ruíz et al., 2020), Chihuahua (PachecoUbaldo et al., 2020), Colima (Barquera et al., 2020b), Durango (González-Medina et al., 2020), Nuevo León (Barquera et al., 2020a), Sinaloa (Clayton et al., 2020), and Sonora (Uribe-Duarte et al., 2020). Mexican Mestizo populations from the Center of Mexico (14 populations): Aguascalientes (Bravo-Acevedo et al., 2020), Guanajuato (Pantoja-Torres et al., 2020), Guerrero (Juárez-Nicolás et al., 2020), Jalisco (Bravo-Acevedo et al., 2020), Mexico City Center, Mexico City Western, Mexico City Eastern, Mexico City Southern, Mexico City Northern (Barquera et al., 2020e), Michoacán (Ballesteros-Romero et al., 2020), Morelos (Ortega-Yáñez et al., 2020), Nayarit (Goné-Vázquez et al., 2020), Querétaro (Martínez-Álvarez et al., 2020), and San Luis Potosí (Hernández-Zaragoza et al., 2020). Mexican Mestizo populations from Southern Mexico (4 populations): Chiapas (Barquera et al., 2020d), Oaxaca (Hernández-Hernández et al., 2020), Quintana Roo (Medina-Escobedo et al., 2020) and Tabasco (Solís-Martínez et al., 2020). Native American Mexican populations (8 populations): Amerindian pooled population 1 (Tarahumaras, Mixtecs, and Zapotecan) (Hollenbach et al., 2001; García-Ortiz et al., 2006) and Amerindian pooled population 2 (Mixtecs and Tarahumaras), Mixe (Hollenbach et al., 2001), Mixtecs (Arnaiz-Villena et al., 2014), Nahuas (Vargas-Alarcón et al., 2003), Lacandon (Barquera et al., 2020f), Seri (Gorodezky, 2006), and Zapotecan (Hollenbach et al., 2001). Non-Mexican Latin-American populations (8 populations): Argentina Amerindian (Cerna et al., 1993), Bolivia Amerindian Aymara*, Colombia*, Costa Rica African-Caribbean (Arrieta-Bolaños et al., 2018), Costa Rica Amerindians (Arrieta-Bolaños et al., 2018), Ecuador*, Nicaragua Managua*, and Panama*.

*Populations from bone marrow or transplantation registry or the dataset is not associated with a publication or has not been yet published. The accessions are detailed in Data Availability Statement.

To establish the populations' similarities and differences in the PCA plot, we generate a discrimination tree that shows high variance features (HLA alleles which frequency, distribution, and representativeness in populations are established as a criterion of discrimination, separation, or conjunction between the evaluated populations). The alleles which differentiate the populations better are showed in the discrimination tree. This is evaluated with the software algorithm base on the frequencies of each allele.

\section{RESULTS}

\section{Clinical and Sociodemographic Characteristics}

The clinical and sociodemographic characteristics of the Mestizo Mexican SLE patients are summarized in Table 1. The SLE patients were $89 \%$ female, and they had a mean age of $39.7 \pm 14.5$ years. While controls were $51 \%$ female, and they had a mean age of $38.0 \pm 15.0$ years. Both groups were considered Mexican Mestizos. The latitude and longitude where the people live were very similar for both groups, took from The Allele Frequency Net Database (AFND). This data was important to validate that both groups are possible exposed to the same disease triggers in the same area. Both SLE and controls were cataloged as urban, which reports a similar utility. The lifestyle and habits could be another factor to restrict the exposition to the same triggers.

The socioeconomic status was defined with an instrument that allowed classifying SLE and Controls as low and middle socioeconomic strata individuals in similar proportions.

The general healthy state in the patients was corroborated by ACR classification, SLEDAI, and SDI questionaries with the clinical and history evaluation of the Rheumatologist. Different SLE phenotypes were found and are detailed in Table 1. Most of the patients showed over one clinical phenotype. The most common were arthritis (79.8\%), renal (65.6\%), and hematological (64.8\%). The mean age of disease onset was $24.5 \pm 11.2$ years, and $34.5 \%$ of the patients 
presented a concomitant autoimmune disease. The most frequent were Graves' disease and hypothyroidism. Other conditions less frequent were Sjogren's syndrome, autoimmune acquired hemophilia, neuromyelitis optica, vitiligo, and scleroderma.

The healthy state of controls was verified by questionnaire. All participants expressed good self-perceived health: no diseases or chronic treatments and no impediment to daily activities.

\section{Genetic Diversity and Admixture}

As expected, the HLA-B and HLA-DRB1 loci were the most polymorphic in both groups, whereas HLA-DQB1 was the least polymorphic locus. Diversity parameters, polymorphic information content, expected and observed heterozygosity values are shown in Table 2. Hardy-Weinberg Equilibrium analysis is displayed with the $\mathrm{p}$ corrected for each locus. HLADRB1 locus tends to have a marginal deviation from HardyWeinberg equilibrium after Bonferroni correction, which is being studied more deeply.

Systemic lupus erythematosus patients have a higher nonautochthonous HLA gene load, while controls have a higher Mexican Native American HLA gene load. We performed the admixture estimations with the Maximum Likelihood method based on HLA-B and -DRB1 of four digits for each included population. HLA-B is the most polymorphic locus and, most of the time, is selected for admixture estimations. Besides, HLADRB1 is the locus most associated with autoimmunity. Both loci analyses conduct to the same conclusion: SLE patients have a higher proportion of Southwestern European ancestry, $48 \pm 8 \%$ (Mean proportion between HLA-B and HLA-DRB1 \pm Standard deviation) than healthy individuals, $30 \pm 7 \%$. Instead, SLE patients have a minor proportion of Mexican Native American ancestry, $44 \pm 1 \%$ than healthy individuals $63 \pm 4 \%$ and the Sub-Saharan African component appears to have a more similar distribution between SLE and controls $7 \pm 7 \%$ and $6 \pm 7 \%$, respectively. The Asian admixture proportions are not showed; it was minimal. Detailed data for HLA-B and HLA-DRB1 are shown in Figure 1.

\section{Genetic Distances}

As expected, because the admixed populations (SLE and healthy individuals) belong to the same region, the variations in genetic distances are low. However, the variations are consistent

TABLE 2 | Estimations of genetic diversity of HLA class I and class || loci in SLE patients and healthy Individuals.

\begin{tabular}{|c|c|c|c|c|c|c|c|c|}
\hline \multirow[t]{2}{*}{ HLA-locus } & \multicolumn{4}{|c|}{ SLE } & \multicolumn{4}{|c|}{ Healthy individuals } \\
\hline & EH & $\mathrm{OH}$ & $p C$ & PIC & EH & $\mathrm{OH}$ & $p C$ & PIC \\
\hline A & 0.9060 & 0.9697 & 0.201 & 0.9002 & 0.8919 & 0.8718 & 0.531 & 0.9761 \\
\hline C & 0.8922 & 0.9571 & 0.352 & 0.8879 & 0.8947 & 0.9009 & 0.196 & 0.9907 \\
\hline B & 0.9654 & 0.9929 & 0.833 & 0.9608 & 0.9668 & 0.9487 & 0.216 & 0.9767 \\
\hline DRB1 & 0.9249 & 0.9489 & 0.080 & 0.9190 & 0.9193 & 0.9013 & 0.010 & 0.8350 \\
\hline DQB1 & 0.8610 & 0.9203 & 0.696 & 0.8600 & 0.8256 & 0.8205 & 0.269 & 0.9447 \\
\hline
\end{tabular}

pC, $p$ corrected value after Bonferroni correction; $\mathrm{OH}$, observed heterozygosity; $E H$, expected heterozygosity; PIC, polymorphic information content. with the admixture analysis and showed statistical significance $(p \mathrm{C}<0.05)$. Nei's distances $(\mathrm{d})$ have shown that SLE patients are closer to non-autochthonous populations (Southwestern European, Sub-Saharan African, and Eastern Asian) than healthy individuals, while healthy individuals are closer to autochthonous populations than the SLE group (Figure 2). Also, calculating the corrected average pairwise distance between populations gave the same information obtained through Nei's distance. Additionally, the average number of pairwise differences within populations was considered to validate each populations' genetic structure. As it is shown, the most isolated Mexican Native American groups (Seri, Lacandon, and Mixe, which are Mexican Native American groups that are geographically and culturally independent from other Mexican populations, implies a reduced or null gene flow from and to these populations, and consequently reduced diversity) showed fewer intra-group differences. These results are shown in a color matrix. The values corresponding to admixed groups (SLE and healthy) have been included in the matrix. The entire matrix values are shown in Supplementary Information 1 as population average pairwise differences $(\pi)$. The same conclusions were reached with other genetic structure analysis as FST value, coancestry coefficients, and Slatkin linearized FSTs (Supplementary Figures 1-3).

Further evidence of the differentiated distribution of immunogenetic diversity in Mexican mestizo groups (SLE and healthy individuals) can be seen in the principal component analysis (PCA) graph. Populations from three continental locations with HLA-B data were considered to construct the PCA. The objective was to visualize the differences between LES and Controls better. We opted to generate a visual discrimination tree, which calls the strongest elements that differentiate the included populations. The PCA point distribution is consistent with ethnic differences among the included populations. The separation of SLE and controls is consistent with the analysis of genetic distances. But it is observed that both the SLE groups and the controls are in the area of the plot where other groups of Mexican mestizos of Mexico City are found (MxCC, $\mathrm{MxCW}, \mathrm{MxCE}, \mathrm{MxCS}, \mathrm{MxCN}$, and MxCS; Centro Ciudad de México, West, East, South, and North, respectively). The distribution of the groups of Mexican mestizos in the PCA shows previous knowledge about Mexican mestizos. The northern states have higher European ancestry, while the southeast has more similarities among Mexican Native Americans (Figure 3).

Additionally, it can be observed how the Native American groups of Mexico present important differences with the mestizo populations. The genetics of Mexico recapitulates the substructure of the Native Americans and affects the biomedical traits. Therefore, although they seem distant and little related, these autochthonous populations confer complexity to the Mexican admixture. Thus, the immunogenetic diversity of the HLA system in Mexico correlates with the genetic structure of the underlying population (Figure 3).

HLA-A ${ }^{*}$ 29:02 C $\mathrm{C}^{*} 16: 01 \sim \mathrm{B}^{*} 44^{*} 03 \sim \mathrm{DRB} 1^{*} 07: 01 \sim \mathrm{DQB}{ }^{*} 02$ : 02 as a novel $\mathrm{CEH}$ of susceptibility identified in Mexican SLE patients.

The determination of allele and haplotype frequencies and the risk or protection conferred by the HLA alleles and haplotypes 


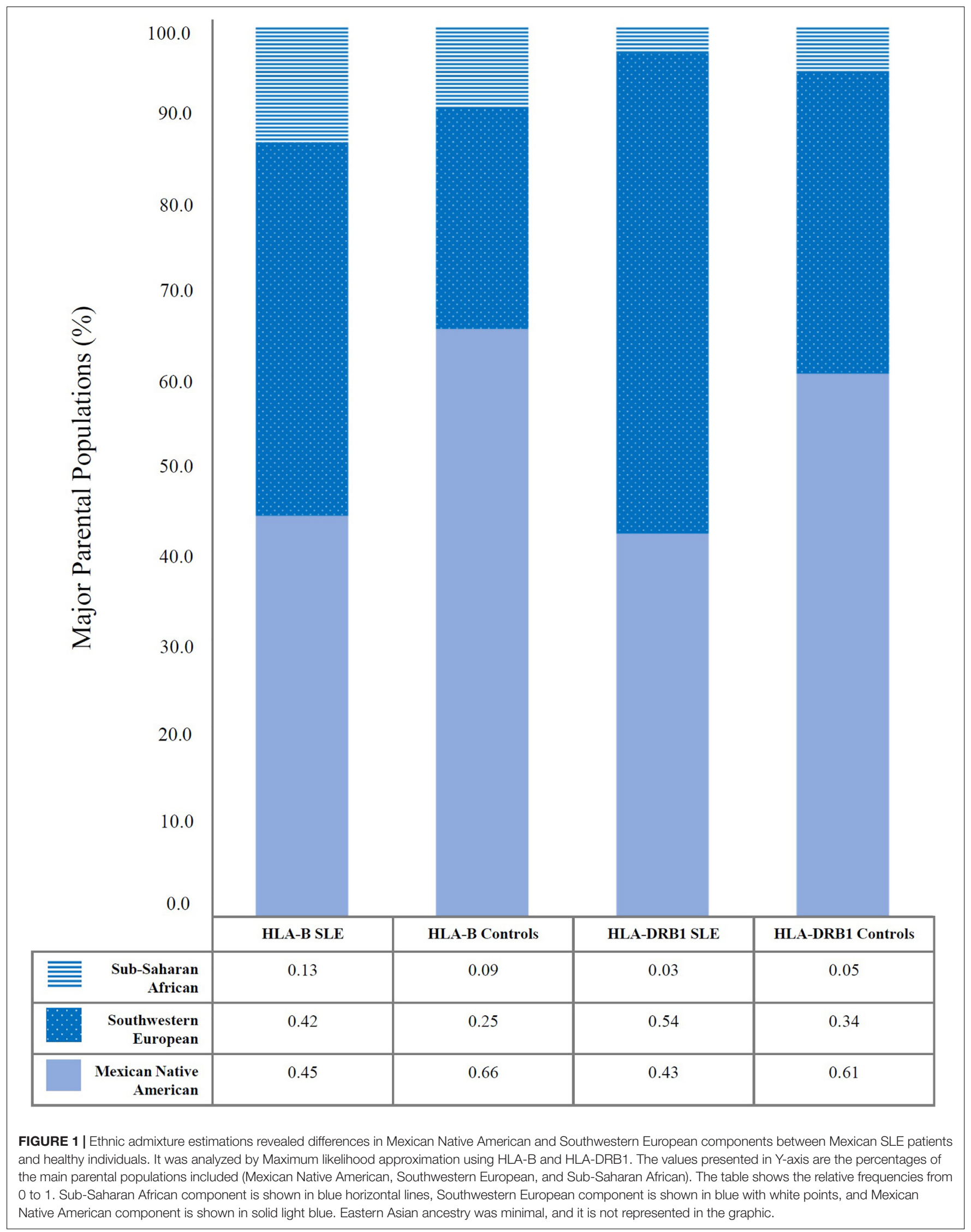




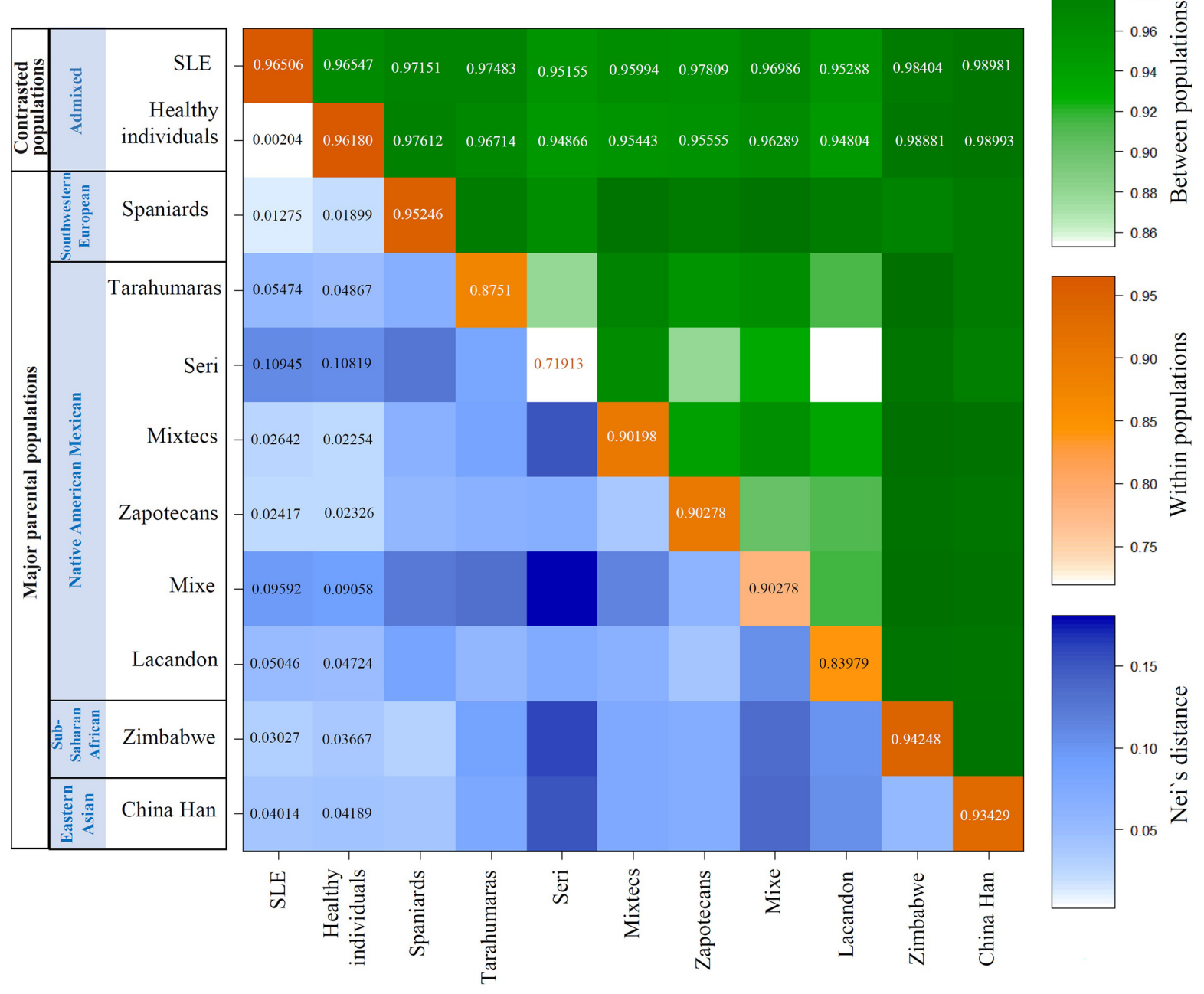

FIGURE 2 | Genetic distances revealed differences in Mexican Native American and Southwestern European ancestry between the SLE and healthy individuals. In this matrix, we represent three different color scales, the average number of pairwise differences ( $\pi$ ) between populations. Orange on diagonal: $\pi$ within populations; Green above diagonal: $\pi x y$ between pairs of populations Blue below diagonal: net number of nucleotide differences between populations (Nei's distance). The interpretation is the same for the three scales; it is shown in the right color bars. To $>$ value $>$ genetic distance. To $>$ intensity color $>$ genetic distance.

are shown in Tables 3-7 and Supplementary Tables 1-4. We found the frequency of a novel susceptibility haplotype incremented in SLE patients. The European block HLA$\mathrm{A}^{*}$ 29:02 $\mathrm{C}^{*} 16: 01 \sim \mathrm{B}^{*} 44^{*} 03 \sim \mathrm{DRB} 1^{*} 07: 01 \sim \mathrm{DQB}{ }^{*} 02: 02$ with $p \mathrm{C}=0.02, \mathrm{OR}=6.7$ (Table 7). None of the individual alleles that make up this $\mathrm{CEH}$ showed statistical significance in this study.

The CEH HLA-A*01:01 C $\mathrm{C}^{*}$ 07:01 $\sim \mathrm{B}^{*} 08: 01 \sim \mathrm{DRB1}^{*} 03: 01 \sim$ $\mathrm{DQB1}^{*} 02: 01$ is the highest risk factor to develop SLE in Mexicans mestizo patients from Mexico City. As shown in previous studies in low-resolution HLA typing (Granados et al., 1996; Vargas-Alarcón et al., 2001; Graham et al., 2007) and the current one in high-resolution HLA typing, the European conserved extended haplotype HLA-A*01:01 C 07:01 $\sim \mathrm{B}^{*} 08: 01 \sim \mathrm{DRB1}^{*}$ 03:01 DQB1 ${ }^{*} 02: 01$ $(p \mathrm{C}=0.0004, \mathrm{OR}=18.7)$ has been found as the high-risk factor to develop SLE in Mexicans from Mexico City (Table 7).
The individual loci statistical analysis has identified relative risks given by each of the alleles that compound this $\mathrm{CEH}$ (Figure 4). The relative risk observed is highly influenced by linkage disequilibrium with neighboring risk genes, both HLA and non-HLA (Supplementary Figure 4). Additionally, the allele HLA-A*11:01 was found as a risk factor with no haplotype linkage, with $p \mathrm{C}=0.035, \mathrm{OR}=2.5$ (Figure 4 and Supplementary Table 1). This allele has previously identified in Malays and Chinese SLE patients (Mohd-Yusuf et al., 2011).

HLA-DRB1*14:06 DQB1*03:01 and -DRB1*16:02 DQB1* 03:01 the protective Mexican Native American haplotypes which frequency is diminished in SLE patients from Mexico City, as it is shown in previous studies (Salgado-Galicia et al., 2020) and the current one. The HLA-DRB1*14 has been previously found in Asians as -DRB1*14:03 (Furukawa et al., 2014). The frequency of HLA class II protective alleles HLA-DRB1*14:06 


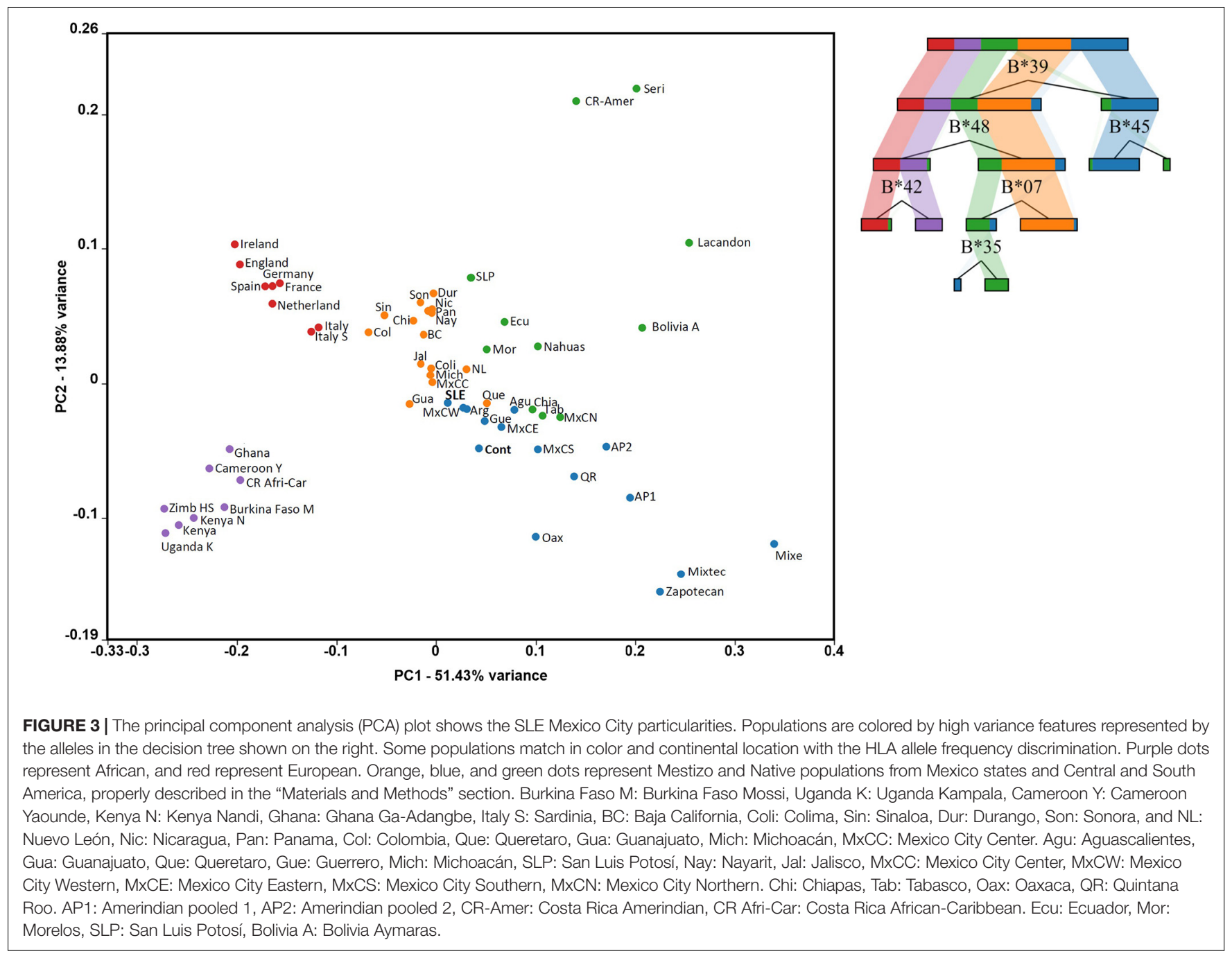

$(p \mathrm{C}=0.006, \mathrm{OR}=0.4)$ and HLA-DRB1 ${ }^{*} 16: 02(p \mathrm{C}=0.006$, $\mathrm{OR}=0.3$ ) were found diminished in the SLE group (Table 4). The Mexican Native American haplotypes, showed protection, the HLA-DRB1 ${ }^{*} 14: 06 \sim \mathrm{DQB} 1{ }^{*} 03: 01(p \mathrm{C}=0.007, \mathrm{OR}=0.4)$ and HLA-DRB1 ${ }^{*} 16: 02 \sim \mathrm{DQB} 1{ }^{*} 03: 01(p \mathrm{C}=0.006, \mathrm{OR}=0.3)$ (Tables 5, 6).

\section{DISCUSSION}

The HLA sequencing has led both to identify a new susceptibility block HLA-A*29:02 C C $^{*}$ 16:01 B* $44^{*} 03 \sim \mathrm{DRB}^{*}$ 07:01 DQB1 ${ }^{*} 02: 02$ and to determine the admixture print which distinguishes patients and healthy individuals in Mexico City. Therefore, alleles and haplotypes of susceptibility and protection found, both the previously described and the new one, will be analyzed, emphasizing discussing the influence of ethnic admixture and the genetic load of parental populations in the development of lupus.

The $\mathrm{CEH}$ associated for the first time with SLE development in Mexicans was the HLA-A*29:02 $C^{*} 16: 01 \sim$ $\mathrm{B}^{*} 44^{*} 03 \sim \mathrm{DRB} 1 * 07: 01 \sim \mathrm{DQB} 1^{*} 02: 02$. This $\mathrm{CEH}$ has been cataloged in previous studies as European (Szilágyi et al., 2010). Only the isolated allele HLA-DRB ${ }^{*} 07$ has been previously associated with antiphospholipid syndrome in SLE patients from Mexico City (Granados et al., 1997). However, this CEH has been a risk factor in Mexican patients diagnosed with Achalasia (Furuzawa-Carballeda et al., 2018). This condition is a motility disorder of the esophagus with abnormalities in the neurons that controls peristaltic movements, whose underlying cause is unknown. Notably, previous studies conducted in other populations suggested that achalasia patients have increased frequency of HLA-DRB1*15 and -DQB1(eight-amino-acid insertion in the cytoplasmic tail of HLA-DQ $\beta 1$ ) alleles in an ethnicity-specific manner. This fact proposes an immunogenetic mechanism (Verne et al., 1999; Gockel et al., 2014; Becker et al., 2016). However, in this study, no SLE patient who carries this $\mathrm{CEH}$ showed some achalasia symptomatology. Probably, the immunosuppressive treatment might mask achalasia symptoms or prevents the development in predisposed individuals. A congruent reason could be that the mean age of achalasia onset in Mexicans ( $42.3 \pm 15.8$ years) is slightly superior to SLE (26.5 \pm 12.2 years). The data needs further research because the shared susceptibility conferred by this $\mathrm{CEH}$ could mean a 
TABLE 3 | Human leukocyte antigen-B allele frequencies in SLE patients and healthy individuals.

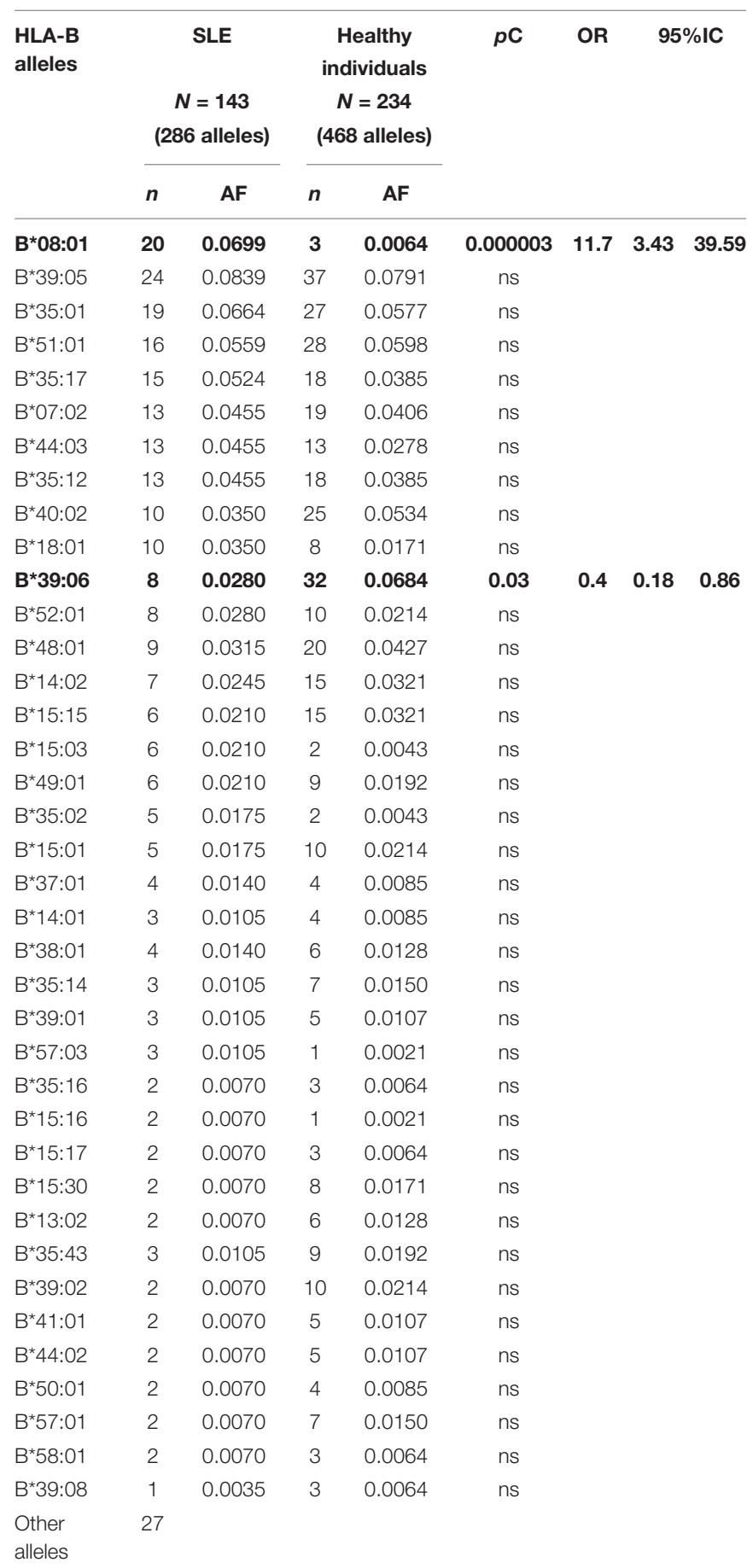

$A F$, allele frequency; ns, not significant; $p C, p$ corrected value using Bonferroni method; OR, odds ratio; $95 \% \mathrm{Cl}, 95 \%$ confidence interval; $\boldsymbol{N}$, total number of individuals; $\boldsymbol{n}$, absolute frequency for each allele. Bold text highlights the results with statistical significance.

share immunopathological mechanism depending on ethnic background. The onset of either lupus or achalasia could rely on the triggers, which might differ for each condition.
TABLE 4 | Human leukocyte antigen-DRB1 allele frequencies in SLE patients and healthy individuals.

\begin{tabular}{|c|c|c|c|c|c|c|c|c|}
\hline \multirow[t]{2}{*}{$\begin{array}{l}\text { HLA-DRB1 } \\
\text { alleles }\end{array}$} & & $\begin{array}{l}=143 \\
\text { alleles) }\end{array}$ & \multicolumn{2}{|c|}{$\begin{array}{c}\text { Healthy } \\
\text { individuals }\end{array}$} & \multirow[t]{2}{*}{$p C$} & \multirow[t]{2}{*}{ OR } & \multicolumn{2}{|c|}{$95 \%$ IC } \\
\hline & $n$ & AF & $n$ & AF & & & & \\
\hline DRB1*08:02 & 52 & 0.1818 & 91 & 0.1944 & ns & & & \\
\hline DRB1*04:07 & 27 & 0.0944 & 55 & 0.1175 & ns & & & \\
\hline DRB1*03:01 & 29 & 0.1014 & 15 & 0.0321 & 0.0002 & 3.4 & 1.79 & 6.47 \\
\hline DRB1*07:01 & 24 & 0.0839 & 33 & 0.0705 & ns & & & \\
\hline DRB1*15:01 & 20 & 0.0699 & 17 & 0.0363 & ns & & & \\
\hline DRB1*04:04 & 17 & 0.0594 & 31 & 0.0662 & ns & & & \\
\hline DRB1*11:04 & 10 & 0.0350 & 8 & 0.0171 & ns & & & \\
\hline DRB1*13:01 & 11 & 0.0385 & 12 & 0.0256 & ns & & & \\
\hline DRB1*14:06 & 12 & 0.0420 & 47 & 0.1004 & 0.006 & 0.4 & 0.20 & 0.75 \\
\hline DRB1*01:01 & 8 & 0.0280 & 9 & 0.0192 & ns & & & \\
\hline DRB1*04:11 & 7 & 0.0245 & 9 & 0.0192 & ns & & & \\
\hline DRB1*16:02 & 5 & 0.0175 & 30 & 0.0641 & 0.006 & 0.3 & 0.10 & 0.68 \\
\hline DRB1 ${ }^{*} 04: 01$ & 3 & 0.0105 & 3 & 0.0064 & ns & & & \\
\hline DRB1*11:02 & 4 & 0.0140 & 4 & 0.0085 & ns & & & \\
\hline DRB1*13:03 & 5 & 0.0175 & 3 & 0.0064 & ns & & & \\
\hline $\mathrm{DRB}^{*}{ }^{* 14: 02}$ & 5 & 0.0175 & 11 & 0.0235 & ns & & & \\
\hline DRB1*04:05 & 3 & 0.0105 & 1 & 0.0021 & ns & & & \\
\hline DRB1*08:04 & 3 & 0.0105 & 2 & 0.0043 & ns & & & \\
\hline DRB1*15:03 & 4 & 0.0140 & 1 & 0.0021 & ns & & & \\
\hline DRB1*01:02 & 4 & 0.0140 & 11 & 0.0235 & ns & & & \\
\hline DRB1*01:03 & 3 & 0.0105 & 3 & 0.0064 & ns & & & \\
\hline $\mathrm{DRB} 1{ }^{*} 04: 02$ & 4 & 0.0140 & 10 & 0.0214 & ns & & & \\
\hline DRB1*08:01 & 2 & 0.0070 & 1 & 0.0021 & ns & & & \\
\hline DRB1*09:01 & 2 & 0.0070 & 1 & 0.0021 & ns & & & \\
\hline DRB1*12:01 & 1 & 0.0035 & 2 & 0.0043 & ns & & & \\
\hline DRB1*13:04 & 2 & 0.0070 & 1 & 0.0021 & ns & & & \\
\hline DRB1*04:03 & 1 & 0.0035 & 10 & 0.0214 & ns & & & \\
\hline DRB1 ${ }^{\star} 04: 08$ & 2 & 0.0070 & 1 & 0.0021 & ns & & & \\
\hline $\mathrm{DRB} 1{ }^{*} 04: 10$ & 1 & 0.0035 & 2 & 0.0043 & ns & & & \\
\hline DRB1*11:01 & 1 & 0.0035 & 6 & 0.0128 & ns & & & \\
\hline DRB1*13:02 & 3 & 0.0105 & 10 & 0.0214 & ns & & & \\
\hline DRB1*13:05 & 1 & 0.0035 & 1 & 0.0021 & ns & & & \\
\hline DRB1*16:01 & 1 & 0.0035 & 2 & 0.0043 & $\mathrm{~ns}$ & & & \\
\hline DRB1*12:02 & 1 & 0.0035 & 3 & 0.0064 & $\mathrm{~ns}$ & & & \\
\hline $\mathrm{DRB}^{*}{ }^{*} 14: 01$ & 1 & 0.0035 & 8 & 0.0171 & ns & & & \\
\hline Other alleles & 7 & & & & & & & \\
\hline
\end{tabular}

$\boldsymbol{A F}$, allele frequency; $n s$, not significant; $p \boldsymbol{C}, p$ corrected value using Bonferroni method; OR, odds ratio; $95 \% \mathrm{Cl}, 95 \%$ confidence interval; $\mathbf{N}$, total number of individuals; $n$, absolute frequency for each allele. Bold text highlights the results with statistical significance.

Achalasia onset has been associated with varicella herpes zoster virus previous infection (Becker et al., 2016). In contrast, SLE development has been associated with other viruses' infections as Epstein-Barr virus (EBV), parvovirus B19 (B19V), and human endogenous retroviruses (HERVs) (Quaglia et al., 2021). Interestingly, the novel haplotype associated with SLE in Mestizo Mexicans from Mexico City is in $2.8 \%$ of these individuals, while only in $0.43 \%$ of healthy Mexicans, $3.42 \%$ 
TABLE 5 | Frequencies of HLA-DRB1 DQB1 haplotypes in SLE patients and healthy individuals.

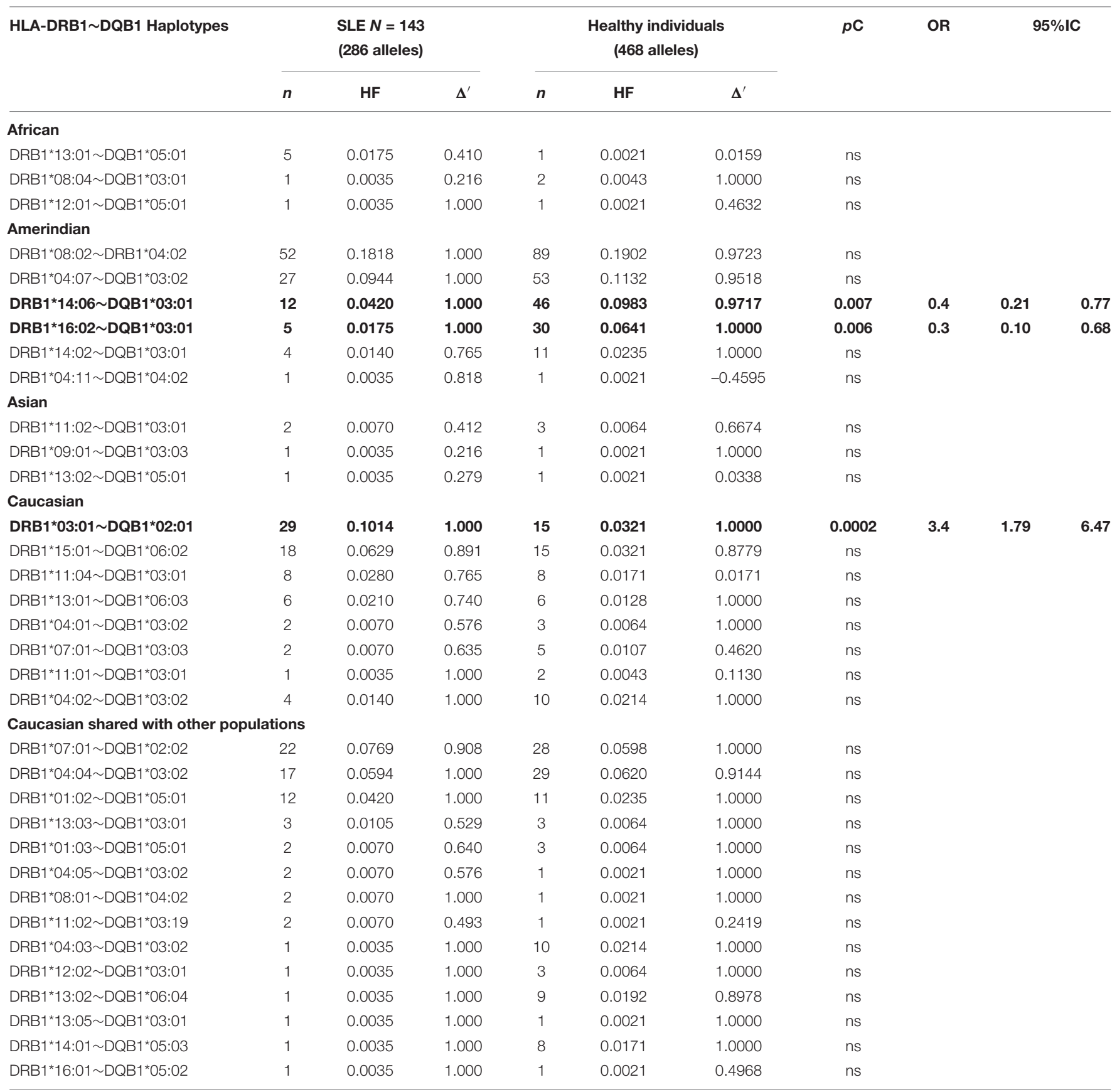

HF, haplotype frequency; ns, not significant; $p$ C, $p$ corrected value using Bonferroni method; OR, odds ratio; $95 \% \mathrm{Cl}$, $95 \%$ confidence interval. $\mathbf{N}$, total number of individuals, $\boldsymbol{n}$, absolute frequency for each allele; $\Delta^{\prime}$, linkage disequilibrium value. Bold text highlights the results with statistical significance.

in Spaniards (Enrich et al., 2019), and surprisingly in 3.84\% of Achalasia Mexican patients (Furuzawa-Carballeda et al., 2018). Therefore, the increased frequency of this new haplotype in Mexican Mestizo patients may represent the convenience of preserving this haplotype as an immunological advantage against pathogens.

On the other hand, it is observable that the percentages of this haplotype in SLE and Achalasia Mexicans are similar to healthy Spaniards. So, we would expect scenarios with similar prevalence and disease phenotypes if it only depended on HLA susceptibility alleles. Unfortunately, there are no official statistics about the prevalence and incidence of SLE in Mexico. Still, reports of SLE in Hispanics show high SLE prevalence in Hispanics than Spaniards (138/100000 and 17.5 to $34.1 / 100000$ per inhabitants per year, respectively) (Atisha-Fregoso et al., 2011; Izmirly et al., 2017; Rees et al., 2017). Furthermore, some severe manifestations such as kidney damage are also more evident in Hispanics (62\%) than Caucasian patients (25\%). 
TABLE 6 | Frequencies of HLA-C B DRB1 DQB1 haplotypes in SLE patients and healthy individuals.

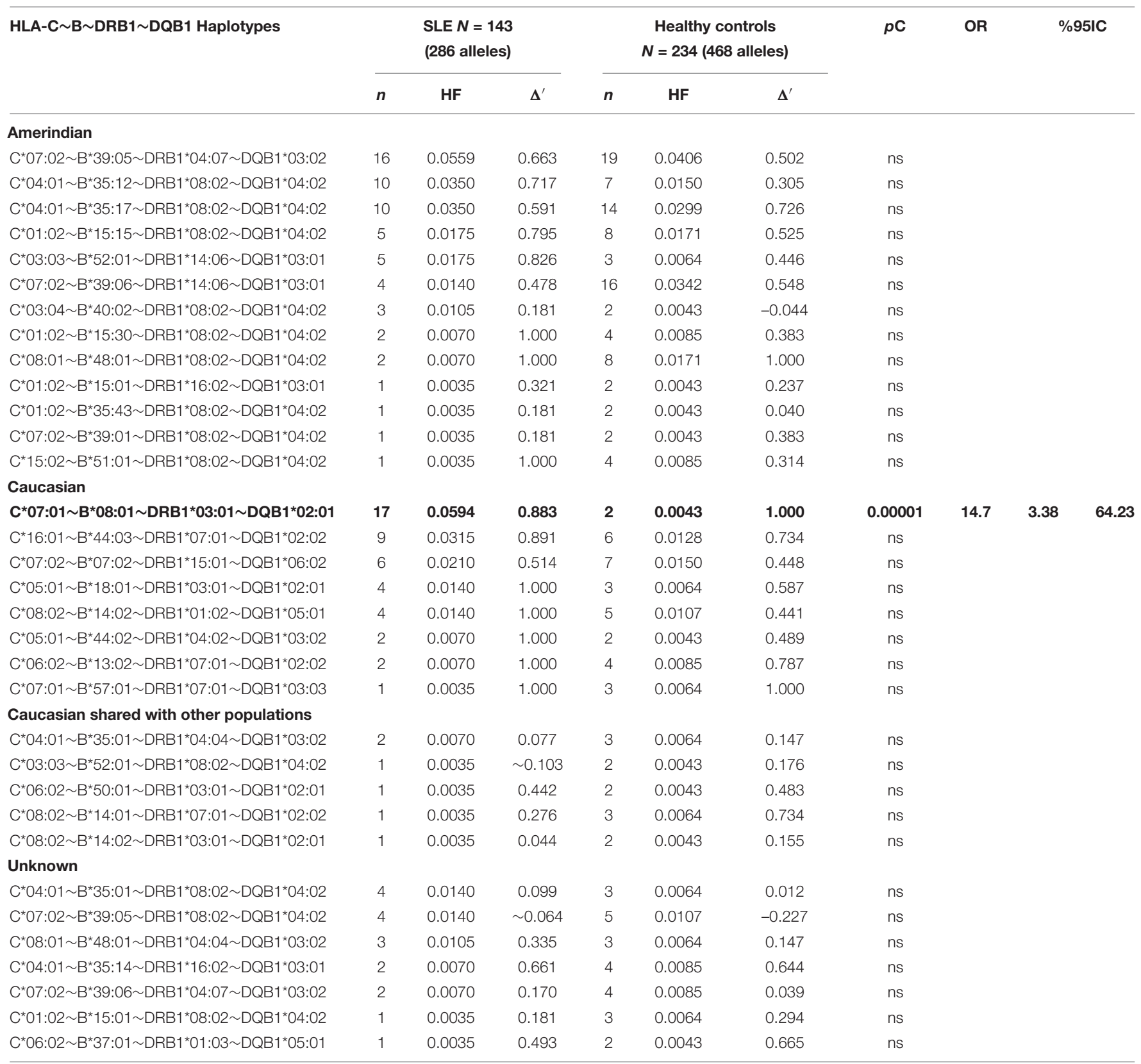

HF, haplotype frequency; $n s$, not significant; $P C$, $p$ corrected value using Bonferroni method; OR, odds ratio; $95 \% \mathrm{Cl}$, 95\% confidence interval. N, total number of individuals, $n$, absolute frequency for each allele; $\Delta^{\prime}$, Linkage disequilibrium value. Bold text highlights the results with statistical significance.

In addition, activity disease score as Systemic Lupus Activity Measure revised (SLAM-R) has been found highest in Hispanic than Caucasian patients (Fernández et al., 2007). Thus, all the above shows that the severity and clinical manifestations differ in an ethnic-dependent manner even when susceptibility haplotypes like the one found in this study are shared between populations. Therefore, the importance of population genetic studies and admixture estimations on Countries with high variability as Mexico is. No less important, there is a conjunction of variables as the availability and access to medical services and treatments that modify the severity phenotype in different populations. This factor always is important to consider before concluding about ethnicity and admixture disparities among populations.

The ethnic background and admixture influence the development of SLE and autoimmunity in Mexicans. This assumption was introduced because the haplotype HLA-B8-DR3 is found in high frequencies in the Caucasian population and has a considerable prevalence of SLE and other autoimmune diseases (Awdeh et al., 1983; Alper et al., 1986; Szilágyi et al., 2010). In contrast, the Mexican Native American populations lack both the HLA-B8-DR3 haplotype and SLE cases. Therefore, the high 
TABLE 7 | Frequencies of HLA $\sim \mathrm{A} \sim \mathrm{C} / \sim \mathrm{B} / \sim \mathrm{DRB} 1 / \sim \mathrm{DQB1}$ haplotypes in SLE patients and healthy individuals.

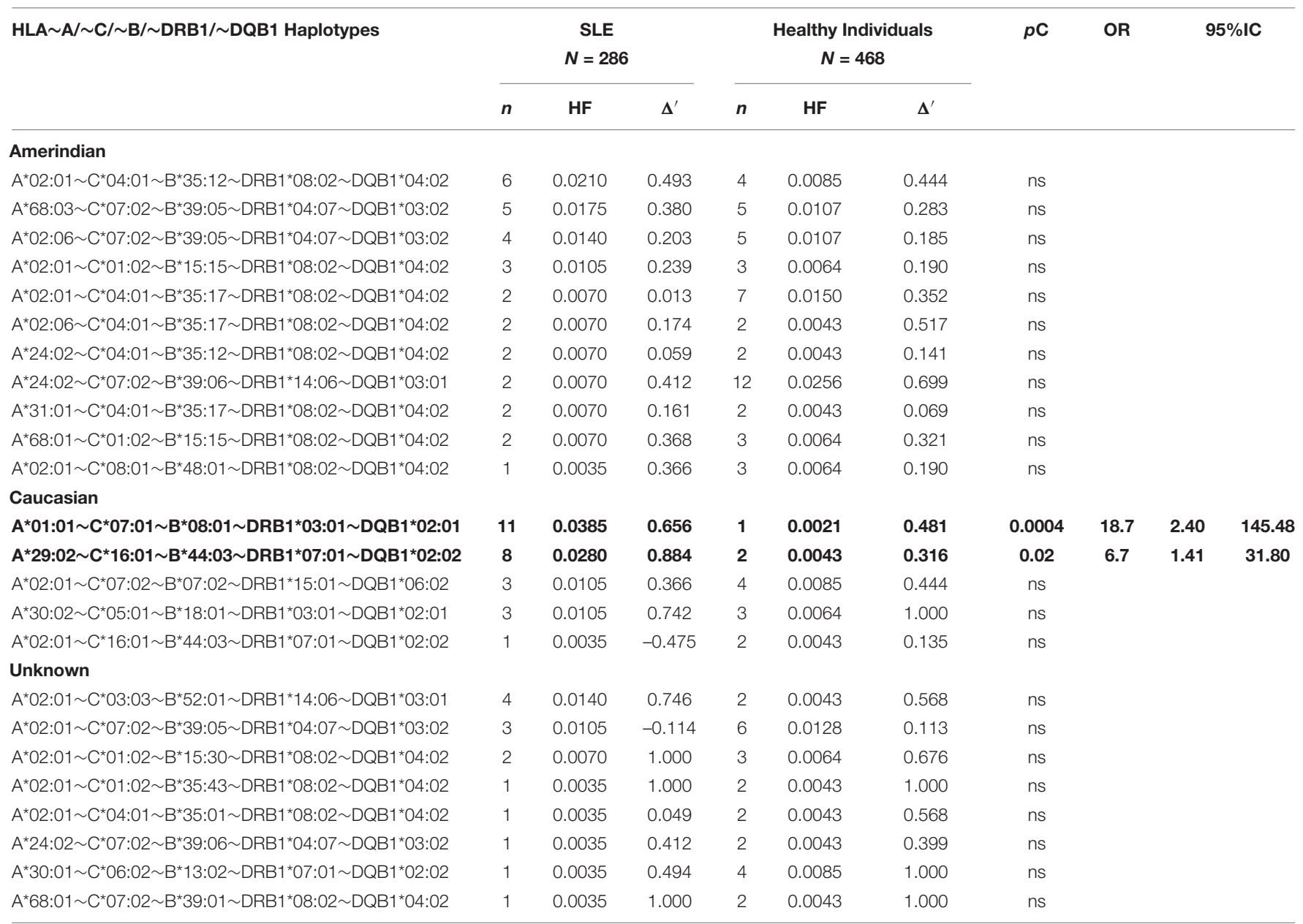

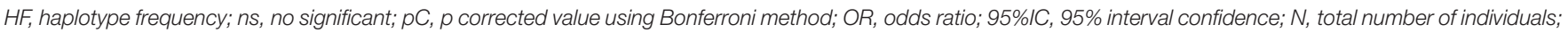
$n$, absolute frequency for each allele; $\Delta^{\prime}$, Linkage disequilibrium value. Bold text highlights the results with statistical significance.

frequency of HLA-B8-DR3 in SLE Mexican patients from Mexico City has been explained as the product of the introduced alleles and haplotypes during the Spaniard's arrival to the Americas. Surprisingly, SLE is more prevalent and aggressive in Mexicans than Europeans. Since the origin of the susceptibility alleles is from Europeans, it would be expected that the severity of the disease and the phenotypes would be similar. However, many elements can intervene to generate a unique scenario in Mexico. For example, the specific interaction of Amerindian, European, and other populations genes influenced by the architecture and tridimensional arrangement of the genes in each mixed population. Not least, the pressure exerted by local triggers and the environment itself.

The complex scenario of autoimmunity in Mexico is framed in that the susceptibility varies as the ethnic admixture pattern does. It has been corroborated in SLE studies. For example, SLE Mestizo patients in Guadalajara (northwestern Mexico) have the haplotype HLA-DRB1*15-DQA1*01:02-DQB1*06:02 as a susceptibility factor (Cortes et al., 2004) while SLE Mestizo patients from Tapachula, Chiapas (southeast of Mexico) have the susceptibility alleles HLA-DRB1*15 and -DRB1*16
(Sepúlveda Delgado et al., 2018). But neither in Guadalajara nor in Tapachula, the HLA-DRB1*03:01 is a susceptibility factor. However, HLA-DRB1*03:01 is one of the main susceptibility alleles found in this study and other previously conducted in Mexico City (Granados et al., 1996; Vargas-Alarcón et al., 2001). Parallel to these susceptibility differences, independent studies of population genetics have demonstrated de admixture variability among Guadalajara, Tapachula, and Mexico City (current study). The Native American Mexican load in Guadalajara, Tapachula, and Mexico City is $\sim 44 \%, \sim 72 \%, \sim 63 \%$, respectively, while the European is $\sim 48 \%, \sim 26 \%, \sim 30 \%$, and the African is $\sim 8 \%$, $\sim 2 \%$, $\sim 6 \%$ (Barquera et al., 2020d; Bravo-Acevedo et al., 2020). Therefore, it looks like admixture proportions in each Mexican State or region could drive toward specific susceptibilities for the same disease. However, it is not only the variation of admixture across Mexico. The presence of different triggers in each region could shape a more comprehensive scenery.

Therefore, the influence of admixture variations in SLE susceptibility could be briefly explained as follows: having a more European HLA load increases the chances of carrying a risk haplotype of this origin. Likewise, there are risk 


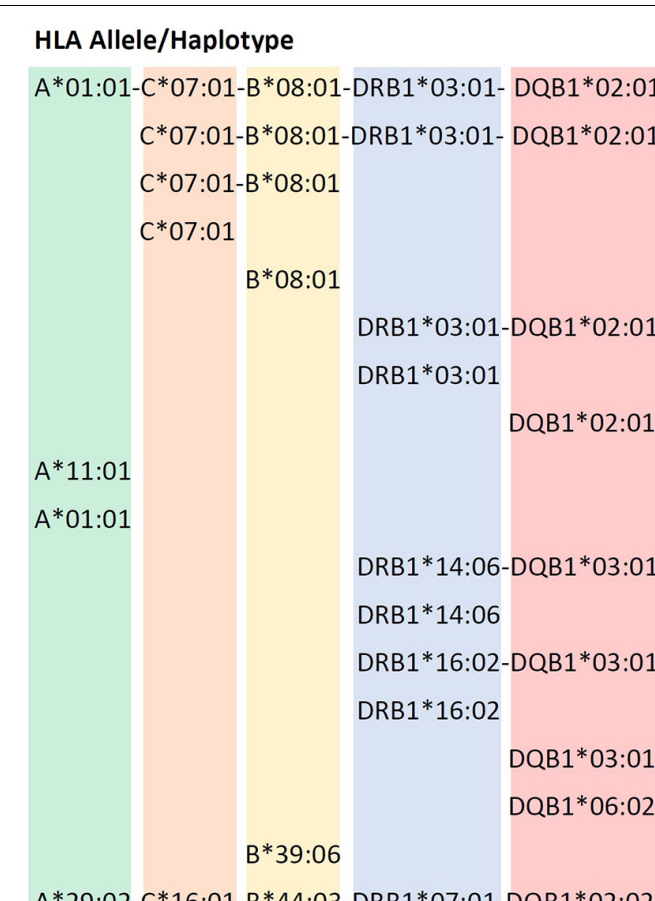

A*29:02-C*16:01-B*44:03-DRB1*07:01-DQB1*02:02

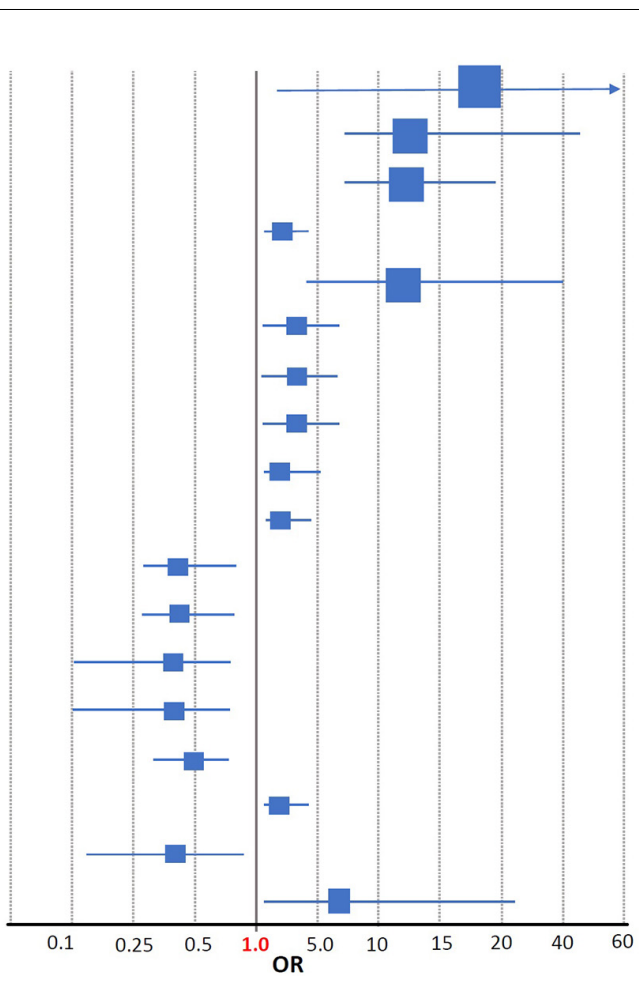

\section{5\%IC}

[2.4-145.48]

[3.38-64.23]

[3.23-37.62]

[1.24-3.73]

[3.43-39.59]

[1.79-6.47]

[1.79-6.47]

[1.79-6.47]

[1.12-5.72]

[1.35-4.79]

[0.21-0.77]

[0.20-0.75]

[0.10-0.68]

[0.10-0.68]

[0.35-0.77]

[1.15-4.24]

[0.18-0.86]

[1.41-31.80]
OR

18.7

14.7

11.0

2.2

11.7

3.4

3.4

3.4

2.5

2.5

0.4

0.4

0.3

0.3

0.5

2.2

0.4

6.7

FIGURE 4 | Human leukocyte antigen susceptibility and protection alleles and haplotypes in Mestizo Mexican SLE patients. The alleles and haplotypes, which showed statistically significant differences between SLE patients and healthy individuals ( $p<0.05)$, are shown in the Forest plot. The Odds ratios and 95\% interval confidence are included in the graphic. Blue boxes are not at scale.

alleles and haplotypes of African and Asian origin; however, because the percentage of these ancestries is low in Mexican Mestizos, they are less likely to carry them. HLA alleles have been conserved in the Mexican Mestizo, probably because they represent an immunological advantage against infections by common pathogens in Mexico. However, the cost of efficiency in pathogen clearance has predisposed to immune hyperresponsiveness, prolonging inflammatory pathways, and leading to autoimmunity. Also, the advance in medicine and better treatments have augmented the survival, life expectancy, and quality of life, which allows the preservation of susceptibility alleles. All the above might be part of the eventual increase in statistics of autoimmune diseases in Mexico, a recent phenomenon caused mainly due to better diagnosis, but influenced by the recently acquired HLAs that have contributed to the fitness of Mexican Mestizos against local pathogens, but with less tolerance to the presence of triggers. This means the carriers of susceptibility alleles or haplotypes are "selected" to manifest the disease based on the presence of the triggers. Therefore, this selection includes individuals with susceptibility alleles and, since those with higher European ancestry are those that most likely have susceptibility alleles; these are the individuals that enrich the autoimmune group.

In truth, there are many assumptions for which further investigation should be carried out. However, the above assumptions could explain why the SLE group differs in admixture proportions compared to control individuals. In studies like the current, it is necessary to ensure the comparability of the groups of patients and controls since useful and accurate results depend on that data quality. Recently published characterization of individuals from Mexico City has been an additional resource to validate the admixture estimations in our control group. In this study were studied 1217 individuals northern $(N=751)$, southern $(N=52)$, eastern $(N=79)$, western $(N=33)$, and central $(N=152)$ Mexico City and surroundings. Admixture estimates are very similar to the calculations performed by Maximum likelihood in our study, being Native American Mexican 63.85\%, European 28.53\%, and African 7.61\% (Barquera et al., 2020e).

Further evidence is shown in the PCA plot; our Mexican admixed samples (SLE and Healthy individuals) are separated from the non-autochthonous populations, which was expected. But, notably, the "Mestizo" sample of SLE patients from Mexico City is not overlapped with Controls.

Systemic lupus erythematosus is closer to non-autochthonous populations, while Healthy individuals are closer to autochthonous populations, congruent with admixture estimations and genetic distances. However, SLE patients retain their identity with the States of Central Mexico, which is expected because SLE patients belong to Mexico City; but, the percentages of ancestry differ, having a greater European load than expected for individuals from Mexico City.

This fact is particularly striking because we are talking about Mestizo Mexican Individuals who share the locality of born and 
the demographic history of settlement (colonial period) but have notable differences in ancestry proportions. This ambivalence in the SLE group could be explained by the fact that the local Native American alleles that confer identity to the Central zone of Mexico are conserved (which is detected in the PCA). At the same time, the advantageous foreign alleles have also been conserved, slightly modifying the proportions of the ancestry of the patients (admixture estimations and genetic distances) and augmenting the possibilities of carrying susceptibility foreign HLA alleles.

The ancestry variation in individuals with SLE, as said before, could mean that some non-autochthonous HLA alleles have been conserved because these alleles represent an immunogenetic advantage, as demonstrated for HLA-DRB1*03. For instance, some naturally processed HLA-DR3-restricted Human herpesvirus 6B (HHV-6B) peptides are recognized broadly with polyfunctional and cytotoxic CD4 T-cell responses (Becerra-Artiles et al., 2019). However, this convenient immunogenetic mechanism for clearing infections might be the detonator for immunological hyperreactivity, which marks the onset of the disease. Viruses infections associated with SLE have been described previously and are ethnically associated with SLE pathogenesis, specific HLA class II alleles, and the development of antinuclear antibodies, the hallmark of SLE have been associated in the same studies (Perl et al., 1995; Magistrelli et al., 1999; Quaglia et al., 2021).

Likewise, Nei's distance data is congruent with the information given by both the susceptibility and protection haplotypes and the admixture analysis. It was found that the SLE group is closer to foreign parental populations (Southwestern European, Sub-Saharan African, and Eastern Asian) than the healthy individuals. In contrast, healthy individuals are nearer to Mexican Native American populations evaluated (Mixtecs, Zapotecans, Tarahumaras, Lacandon, Mixe, and Seri). As expected for intra-specie analysis for the same geographic area, the genetic distance variability is low, but the differences are consistent and significant. Corrected average pairwise differences gave the same information.

The matrix of genetic distances reflects the differences between the Mestizos of Mexico City (SLE and controls), Figure 2. As mentioned before about PCA, SLE and controls are Mestizos from the same geographical area, so it would be expected that there would be no variation in admixture proportions. But indeed, there is. The matrix shows consistent variation indicating SLE patients are genetically more similar to non-autochthonous populations. In comparison, healthy individuals are genetically more similar to Mexican Native American populations. However, some aspects about populations included are worth exploring to substantiate the validity of the comparison.

Regarding the notable genetic variation of the Mexican indigenous groups included, it was expected. The presented Fst matrix and values (Supplementary Figure 1), and the other calculations as coancestry and Slatkin's Fst (Supplementary Figures 2,3), reflect a bit of what has been described for the native populations that inhabited Mexico. It has been corroborated a striking genetic stratification among indigenous populations within Mexico at varying degrees of geographic isolation. Some groups are differentiated as Europeans are from East Asians.
Seris and Lacandons are good examples (Infante et al., 1999; Barquera et al., 2020c); these groups are exposed to high levels of genetic drift and isolation. However, the value of including them as Mexican Native American parental populations is that presentday Mexicans' genetic composition recapitulates ancient Native American substructure, despite the potential homogenizing effect of postcolonial admixture. Fine-scale population structure going back centuries is not merely a property of isolated or rural indigenous communities. Cosmopolitan populations still reflect the underlying genetic ancestry of local native populations, arguing for a strong relationship between the indigenous and the Mexican mestizo population, albeit without the extreme drift exhibited in some current indigenous groups (Moreno-Estrada et al., 2014).

Another notable feature is the genetic distances between the selected non-indigenous populations. Mainly, the Fst indicates an unexpected but explainable closeness between Zimbabwe and the Spanish. The characteristics of the Zimbabwe Harare Shona sample and previous periods of European colonization may have had a specific influence on this population that we cannot trace but hypothesize. Non-local HLA alleles may have been conserved as an immunological advantage, which has already been mentioned for Mexican Mestizos, additional to the MHC Class III genes with immunological functions conserved due to the linkage disequilibrium with the possibly acquired HLA Class I and Class II variants. Therefore, it should be noted that although the European load is likely to be low in this group of sub-Saharan Africans, the variants that contribute to fitness can be conserved and detected in the genetic distance calculations.

Furthermore, estimates of admixture by HLA are robust. In other studies, in Mexico City individuals, the admixture estimates are similar to the current study. It should be noted that these studies used HLA parental populations data different from that used in this study. Estimates with other techniques such as STRs have also generated similar results (JuárezCedillo et al., 2008). Thus, if the selected parental populations agree with the settlement background in Mexico, they can bring us the correct information about admixture and the genetic distances.

Finally, the $\mathrm{CEH}$ described as a susceptibility factor for Europeans the HLA-A*01:01 $\mathrm{C}^{*} 07: 01 \sim \mathrm{B}^{*} 08: 01 \sim \mathrm{DRB}{ }^{*} 02: 01$ $\sim \mathrm{DQB1}{ }^{*} 02: 01$ has been found as a high-risk factor for developing SLE. This CEH has a powerful influence on SLE development and other autoimmune diseases in mestizo Mexican individuals from Mexico City (Granados et al., 1996) and other populations. At first glance, this haplotype's relative risk appears to have a summative effect by the alleles that make up it; as more HLA alleles are added to the haplotype, the risk increases. However, the relative risk conferred by HLA$\mathrm{B}^{*} 08: 01, \mathrm{HLA}-\mathrm{DRB} 1^{*} 03: 01$, and haplotypes containing them confirm that the risk is not summative but conferred by the genes in linkage disequilibrium with these variants. Besides, this linkage has been turned more complicated during the HLA research course. Early in the study of HLA was described a strong linkage disequilibrium not only among HLA genes of the haplotype HLA-B8-DR3 but between HLA and complement 
(C2, C4a, C4b, and Factor B) (Black et al., 1982; Wescott et al., 1987; Picceli et al., 2016). Currently, it is known that a considerable number of variants, mainly of MHC class three, are in linkage disequilibrium with the variants of $\mathrm{B}$ and DR indicated above, which increases the genetic risk load of the individual with lupus.

Models have been developed to confirm the susceptibility conferred by genes in the MHC III region (non-classical HLA and non-HLA genes) linked to HLA-B and -DRB1. The most important linked genes using HLA-DRB1*03:01 as covariant are: the proto-oncogene Notch homologue 4 (NOTCH4), the MHC class I polypeptide-related sequence A and B (MIC-A and MIC-B), the steroid 21-hydroxylase (CYP21A2), (Partanen et al., 1988; Morris et al., 2012) the three $70 \mathrm{kDa}$ heat-shock proteins (HSPA1A, HSPA1B, HSPA1L), (Mišunová et al., 2017), natural cytotoxicity triggering receptor 3 (NCR3); nuclear factor kappa light chain gene enhancer in B cells inhibitor-like 1 (NFKBIL1), allograft inflammatory factor 1 (AIF1) (Dorak et al., 2006); and the three Tumor Necrosis Factor genes (Lymphotoxinbeta, Lymphotoxin-alpha, and TNF- $\alpha$ ) (Zúñiga et al., 2001; Ramírez-Bello et al., 2018). Important variants of the genes mentioned above have been deeply studied in Caucasians, and linkage disequilibrium with HLA-B*08:01 and -DRB1*03:01 has been confirmed (Dorak et al., 2006). This type of study is a prospect to be carried out in the Mexican population to determine the integrity of the $\mathrm{MHC}$ blocks conserved in Mexican Mestizos and how the variants could have been fixed or discarded, giving the specific characteristics of SLE in Mexicans.

\section{CONCLUSION}

In conclusion, the genetic background and the Mexican admixture heterogeneity define part of the dynamic of SLE in Mestizo Mexican patients. Considering the regional distribution of genetic susceptibility and the ethnic barriers can be a useful biomedical tool. Increasingly, the born region and the ethnic admixture (the apparent ethnic phenotypes based on physical characteristics) are considered an element that helps the diagnosis of diseases. Such is the case of neuromyelitis optica and multiple sclerosis, which may be clinically similar but have well-established genetic susceptibility and ethnic differences. In Mexico, the susceptibility to neuromyelitis optica is given by HLA-DRB1*16:02, and it usually occurs in individuals with a high Mexican Native American ancestry (Gorodezky et al., 1986; Romero-Hidalgo et al., 2020) (and usually, the physical characteristics indicate it). But in multiple sclerosis, the susceptibility is mainly given by HLA-DRB1* 15 , and it occurs in individuals with higher Caucasian ancestry (Ordoñez et al., 2015). Another good example includes Multifocal Epithelial Hyperplasia, which depends on genetic susceptibility and is expressed in specific populations with high Mexican Native American components.

On the other hand, the technical aspect of this type of study is important. HLA sequencing study has helped to describe the ethnic admixture load in the patient and control populations. It deepens susceptibility and protection alleles and haplotypes due to high-fidelity performance. Finally, non-HLA variants in the MHC area contribute to the risk through linkage disequilibrium with HLA genes. Therefore, the CEHs help to explain better the susceptibility and protection in groups with known ethnic composition. However, the linkage of these variants with HLA requires a more in-depth analysis to understand how they add risk to $\mathrm{CEH}$ and the specific variants conserved in the Mexican population.

\section{DATA AVAILABILITY STATEMENT}

The datasets presented in this study can be found in the online repository: Allele frequency net database (AFND) with the accession Mexico Mexico City Mestizo population $(n=143)$ (SLE). African: Burkina Faso Mossi $(n=53)$, Cameroon Yaounde $(n=92)$, Ghana Ga-Adangbe $(n=141)$, Kenya $(n=144)$, Uganda Kampala pop $2(n=175)$, Kenya Nandi $(n=240)$, Zimbabwe Harare Shona $(n=230)$. European: England Blood Donors of Mixed Ethnicity $(n=519)$, France Lyon $(n=4813)$, Germany Essen $(n=174)$, Ireland Northern $(n=1000)$, Italy Lombardy $(n=674)$, Italy Sardinia pop $3(n=100)$, Netherlands UMCU $(n=64)$, Spain Catalunya, Navarra, Extremadura, Aragon, Cantabria $(n=4335)$. Mestizo Mexican populations from Northern Mexico: Mexico Baja California, Mexicali $(n=100)$, Mexico Chihuahua Chihuahua City $(n=119)$, Mexico Colima, Colima city $(n=61)$, Mexico Durango, Durango city $(n=153)$, Mexico Nuevo Leon, Monterrey city $(n=266)$, Mexico Sinaloa Rural ( $n=183)$, Mexico Sonora Rural $(n=197)$. Mestizo Mexican populations from the Center of Mexico: Mexico Aguascalientes State $(n=95)$, Mexico Guanajuato Rural $(n=162)$, Mexico Guerrero state $(n=144)$, Mexico Jalisco, Guadalajara city $(n=1189)$, Mexico Mexico City Center $(n=152)$, Mexico Mexico City West $(n=33)$, Mexico Mexico City East $(n=79)$, Mexico Mexico City South $(n=52)$, Mexico Mexico City North $(n=751)$, Mexico Michoacan Rural ( $n=348)$, Mexico Nayarit, Tepic $(n=97)$, Mexico Queretaro, Queretaro city $(n=45)$, Mexico San Luis Potosi Rural $(n=87)$, Mexico Mexico City Mestizo pop $2(n=234)$ (Controls). Mestizo Mexican populations from Southern Mexico: Mexico Chiapas Rural $(n=121)$, Mexico Oaxaca, Oaxaca city $(n=151)$, Mexico Quintana Roo Rural $(n=50)$, Mexico Tabasco Rural $(n=142)$, Native American Mexican populations: Mexico Nahuas $(n=72)$, Mexico Oaxaca Mixe $(n=55)$, Mexico Mixtec $(n=97)$, Mexico Chihuahua Tarahumara $(n=97)$, Mexico Oaxaca Mixe $(n=55)$, Mexico Oaxaca Mixtecs $(n=103)$, Mexico Oaxaca Zapotec $(n=90)$, Mexico Sonora Seri $(n=34)$, Mexico Chiapas Lacandon Mayans $(n=218)$. Non-Mexican Latin-American populations: Argentina Gran Chaco Eastern Toba $(n=125)$, Bolivia La Paz Aymaras $(n=88)$, Colombia Barranquilla $(n=188)$, Costa Rica AfricanCaribbean $(n=102)$, Costa Rica Amerindians $(n=125)$, Ecuador Andes Mixed Ancestry $(n=824)$, Nicaragua Managua $(n=339)$, Panama $(n=462)$. Asian: China Han $(n=314)$ http://www. allelefrequencies.net/ (Gonzalez-Galarza et al., 2020). 


\section{ETHICS STATEMENT}

The studies involving human participants were reviewed and approved by The Ethics Committee from the Instituto Nacional de Ciencias Médicas y Nutrición Salvador Zubirán. Reference No. 1738. The patients/participants provided their written informed consent to participate in this study.

\section{AUTHOR CONTRIBUTIONS}

SH-D, JG, GV-A, and JZ performed the conceptualization of the study. SH-D and JM-G performed the methodology. SH-D, JJ-O, LL, and GL investigated the study. JZ, JG, DR, VT-M, LL, and GL did the contribution with resources. SH-D, JM-G, and VA-A carried out the data curation. SH-D wrote the original draft and visualized the data. SH-D, JG, GV-A, and LL wrote, reviewed, and edited the draft of the manuscript. JZ, GV-A, and JG supervised the project. JG carried out the project administration. JG and JZ carried out the funding acquisition. All authors contributed to the article and approved the submitted version.

\section{REFERENCES}

Alarcón-Riquelme, M. E., Ziegler, J. T., Molineros, J., Howard, T. D., MorenoEstrada, A., Sánchez-Rodríguez, E., et al. (2016). Genome-wide association study in an Amerindian ancestry population reveals novel systemic lupus erythematosus risk loci and the role of European admixture. Arthritis Rheumatol. 68, 932-943. doi: 10.1002/art.39504

Alper, C. A., Awdeh, Z. L., and Yunis, E. J. (1986). Complotypes, extended haplotypes, male segregation distortion, and disease markers. Hum. Immunol. 15, 366-373. doi: 10.1016/0198-8859(86)90013-3

Arnaiz-Villena, A., Vargas-Alarcón, G., Areces, C., Enríquez-de-Salamanca, M., Abd-El-Fatah-Khalil, S., Fernández-Honrado, M., et al. (2014). Mixtec Mexican Amerindians: an HLA alleles study for America peopling, pharmacogenomics and transplantation. Immunol. Invest. 43, 738-755. doi: 10.3109/08820139. 2014.926369

Arrieta-Bolaños, E., Madrigal-Sánchez, J. J., Stein, J. E., Órlich-Pérez, P., MoreiraEspinoza, M. J., Paredes-Carias, E., et al. (2018). High-resolution HLA allele and haplotype frequencies in majority and minority populations of Costa Rica and Nicaragua: Differential admixture proportions in neighboring countries. Hla 91, 514-529. doi: 10.1111/tan.13280

Atisha-Fregoso, Y., Jakez-Ocampo, J., and Llorente, L. (2011). Systemic lupus erythematosus in Hispanics. Autoimmunity 44, 555-561. doi: 10.3109/ 08916934.2011 .592882

Awdeh, Z. L., Raum, D., Yunis, E. J., and Alper, C. A. (1983). Extended HLA/complement allele haplotypes: evidence for T/t-like complex in man. Proc. Natl. Acad. Sci. U.S.A. 80, 259-263. doi: 10.1073/pnas.80.1.259

Ballesteros-Romero, M., Barquera, R., Rodríguez-López, M. E., HernándezZaragoza, D. I., Goné-Vázquez, I., Clayton, S., et al. (2020). Genetic diversity of HLA system in two populations from Michoacán, Mexico: morelia and rural Michoacán. Hum. Immunol. 81, 506-509. doi: 10.1016/j.humimm.2019.05.017

Barquera, R., Bravo-Acevedo, A., Clayton, S., Munguía, T. J. R., HernándezZaragoza, D. I., Adalid-Sáinz, C., et al. (2020a). Genetic diversity of HLA system in two populations from Nuevo León, Mexico: monterrey and rural Nuevo León. Hum. Immunol. 81, 516-518. doi: 10.1016/j.humimm.2019.06.003

Barquera, R., Hernández-Zaragoza, D. I., Arellano-Prado, F. P., Goné-Vázquez, I., Clayton, S., Arrieta-Bolaños, E., et al. (2020b). Genetic diversity of HLA system in two populations from Colima, Mexico: colima city and rural Colima. Hum. Immunol. 81, 513-515. doi: 10.1016/j.humimm.2019.06.004

Barquera, R., Hernández-Zaragoza, D. I., Bravo-Acevedo, A., Arrieta-Bolaños, E., Clayton, S., Acuña-Alonzo, V., et al. (2020c). The immunogenetic diversity of the HLA system in Mexico correlates with underlying population genetic structure. Hum. Immunol. 81, 461-474. doi: 10.1016/j.humimm.2020.06.008

\section{FUNDING}

SH-D was a doctoral student from the Biomedical Sciences Doctoral Program, Universidad Nacional Autónoma de México (UNAM) and has received CONACYT fellowship 619959, Support numbers 463857 and CVU 689031. This work was supported by grant 000000000273175 from the CONACYT (Consejo Nacional de Ciencia y Tecnología de México).

\section{ACKNOWLEDGMENTS}

The authors thank all individuals with SLE and healthy controls who have participated in this genetic study.

\section{SUPPLEMENTARY MATERIAL}

The Supplementary Material for this article can be found online at: https://www.frontiersin.org/articles/10.3389/fgene. 2021.701373/full\#supplementary-material

Barquera, R., Juárez-Nicolás, F., Martínez-Álvarez, J. C., Ponnandai-Shanmugavel, K. S., Hernández-Zaragoza, D. I., Vázquez-Castillo, T. V., et al. (2020d). Genetic diversity of HLA system in two populations from Chiapas, Mexico: tuxtla Gutiérrez and rural Chiapas. Hum. Immunol. 81, 563-565. doi: 10.1016/j. humimm.2019.07.285

Barquera, R., Martínez-Álvarez, J. C., Hernández-Zaragoza, D. I., Bravo-Acevedo, A., Juárez-Nicolás, F., Arriaga-Perea, A. J., et al. (2020e). Genetic diversity of HLA system in six populations from Mexico City Metropolitan Area, Mexico: Mexico City North, Mexico City South, Mexico City East, Mexico City West, Mexico City Center and rural Mexico City. Hum. Immunol. 81, 539-543. doi: 10.1016/j.humimm.2019.07.297

Barquera, R., Zuniga, J., Flores-Rivera, J., Corona, T., Penman, B. S., HernándezZaragoza, D. I., et al. (2020f). Diversity of HLA Class I and Class II blocks and conserved extended haplotypes in Lacandon Mayans. Sci. Rep. 10:3248. doi: 10.1038/s41598-020-58897-5

Becerra-Artiles, A., Cruz, J., Leszyk, J. D., Sidney, J., Sette, A., Shaffer, S. A., et al. (2019). Naturally processed HLA-DR3-restricted HHV-6B peptides are recognized broadly with polyfunctional and cytotoxic CD4 T-cell responses. Eur. J. Immunol. 49, 1167-1185. doi: 10.1002/eji.201948126

Becker, J., Haas, S. L., Mokrowiecka, A., Wasielica-Berger, J., Ateeb, Z., Bister, J., et al. (2016). The HLA-DQ $\beta 1$ insertion is a strong achalasia risk factor and displays a geospatial north-south gradient among Europeans. Eur. J. Hum. Genet. 24, 1228-1231. doi: 10.1038/ejhg.2015.262

Black, C. M., Welsh, K. I., Fielder, A., Hughes, G. R., and Batchelor, J. R. (1982). HLA antigens and Bf allotypes in SLE: evidence for the association being with specific haplotypes. Tissue Antigens 19, 115-120. doi: 10.1111/j.1399-0039.1982. tb01426.x

Bombardier, C., Gladman, D. D., Urowitz, M. B., Caron, D., Chang, C. H., Austin, A., et al. (1992). Derivation of the sledai. A disease activity index for lupus patients. Arthritis Rheumatism 35, 630-640. doi: 10.1002/art.1780350606

Bravo-Acevedo, A., Escobedo-Ruíz, A., Barquera, R., Clayton, S., García-Arias, V. E., Arrieta-Bolaños, E., et al. (2020). Genetic diversity of HLA system in six populations from Jalisco, Mexico: Guadalajara city, Tlajomulco, Tlaquepaque, Tonalá, Zapopan and rural Jalisco. Hum. Immunol. 81, 502-505. doi: 10.1016/j. humimm.2019.05.012

Cao, K., Hollenbach, J., Shi, X., Shi, W., Chopek, M., and Fernández-Viña, M. A. (2001). Analysis of the frequencies of HLA-A, B, and C alleles and haplotypes in the five major ethnic groups of the United States reveals high levels of diversity in these loci and contrasting distribution patterns in these populations. Hum. Immunol. 62, 1009-1030. doi: 10.1016/s0198-8859(01)00298-1

Cao, K., Moormann, A. M., Lyke, K. E., Masaberg, C., Sumba, O. P., Doumbo, O. K., et al. (2004). Differentiation between African populations is evidenced by 
the diversity of alleles and haplotypes of HLA class I loci. Tissue Antigens 63, 293-325.

Carter, E. E., Barr, S. G., and Clarke, A. E. (2016). The global burden of SLE: prevalence, health disparities and socioeconomic impact. Nat. Rev. Rheumatol. 12, 605-620. doi: 10.1038/nrrheum.2016.137

Centers for Disease Control and Prevention (2011). Epi Info ${ }^{T M}$, a Database and Statistics Program for Public Health Professionals. Atlanta, GA: Centers for Disease Control and Prevention.

Cerna, M., Falco, M., Friedman, H., Raimondi, E., Maccagno, A., Fernandez-Viña, M., et al. (1993). Differences in HLA class II alleles of isolated South American Indian populations from Brazil and Argentina. Hum. Immunol. 37, 213-220. doi: 10.1016/0198-8859(93)90504-T

Clayton, S., Barquera, R., Uribe-Duarte, M. G., Goné Vázquez, I., Zúñiga, J., Arrieta-Bolaños, E., et al. (2020). Genetic diversity of HLA system in two populations from Sinaloa, Mexico: culiacán and rural Sinaloa. Hum. Immunol. 81, 482-484. doi: 10.1016/j.humimm.2019.06.006

Cortes, L. M., Baltazar, L. M., Lopez-Cardona, M. G., Olivares, N., Ramos, C., Salazar, M., et al. (2004). HLA class II haplotypes in Mexican systemic lupus erythematosus patients. Hum. Immunol. 65, 1469-1476. doi: 10.1016/j. humimm.2004.09.008

Devilliers, H., Amoura, Z., Besancenot, J. F., Bonnotte, B., Pasquali, J. L., Wahl, D., et al. (2012). LupusQoL-FR is valid to assess quality of life in patients with systemic lupus erythematosus. Rheumatology (Oxford) 51, 1906-1915. doi: 10.1093/rheumatology/kes165

Dorak, M. T., Shao, W., Machulla, H. K., Lobashevsky, E. S., Tang, J., Park, M. H., et al. (2006). Conserved extended haplotypes of the major histocompatibility complex: further characterization. Genes Immun. 7, 450-467. doi: 10.1038/sj. gene. 6364315

Enrich, E., Campos, E., Martorell, L., Herrero, M. J., Vidal, F., Querol, S., et al. (2019). HLA-A, -B, -C, -DRB1, and -DQB1 allele and haplotype frequencies: an analysis of umbilical cord blood units at the Barcelona Cord Blood Bank. Hla 94, 347-359. doi: 10.1111/tan.13644

Escobedo-Ruíz, A., Barquera, R., González-Martín, A., Argüelles-San Millán, J. M., Uribe-Duarte, M. G., Hernández-Zaragoza, D. I., et al. (2020). Genetic diversity of HLA system in four populations from Baja California, Mexico: Mexicali, La Paz, Tijuana and rural Baja California. Hum. Immunol. 81, 475-477. doi: 10.1016/j.humimm.2019.06.007

Excoffier, L., and Lischer, H. E. (2010). Arlequin suite ver 3.5: a new series of programs to perform population genetics analyses under Linux and Windows. Mol. Ecol. Resour. 10, 564-567. doi: 10.1111/j.1755-0998.2010.02847.x

Fernández, M., Alarcón, G. S., Calvo-Alén, J., Andrade, R., McGwin, G. Jr., Vilá, L. M., et al. (2007). A multiethnic, multicenter cohort of patients with systemic lupus erythematosus (SLE) as a model for the study of ethnic disparities in SLE. Arthritis Rheum. 57, 576-584. doi: 10.1002/art.22672

Furukawa, H., Kawasaki, A., Oka, S., Ito, I., Shimada, K., Sugii, S., et al. (2014). Human leukocyte antigens and systemic lupus erythematosus: a protective role for the HLA-DR6 alleles DRB1*13:02 and *14:03. PLoS One 9:e87792. doi: 10.1371/journal.pone.008779

Furuzawa-Carballeda, J., Zuñiga, J., Hernández-Zaragoza, D. I., Barquera, R., Marques-García, E., Jiménez-Alvarez, L., et al. (2018). An original Eurasian haplotype, HLA-DRB1*14:54-DQB1*05:03, influences the susceptibility to idiopathic achalasia. PLoS One 13:e0201676. doi: 10.1371/journal.pone. 0201676

García-Ortiz, J. E., Sandoval-Ramírez, L., Rangel-Villalobos, H., MaldonadoTorres, H., Cox, S., García-Sepúlveda, C. A., et al. (2006). High-resolution molecular characterization of the HLA class I and class II in the Tarahumara Amerindian population. Tissue Antigens 68, 135-146. doi: 10.1111/j.1399-0039. 2006.00636.x

Ghodke-Puranik, Y., and Niewold, T. B. (2015). Immunogenetics of systemic lupus erythematosus: a comprehensive review. J. Autoimmun. 64, 125-136. doi: 10.1016/j.jaut.2015.08.004

Gladman, D. D., Goldsmith, C. H., Urowitz, M. B., Bacon, P., Fortin, P., Ginzler, E., et al. (2000). The systemic lupus international collaborating clinics/American College of Rheumatology (SLICC/ACR) Damage index for systemic lupus erythematosus international comparison. J. Rheumatol. 27, 373-376.

Gockel, I., Becker, J., Wouters, M. M., Niebisch, S., Gockel, H. R., Hess, T., et al. (2014). Common variants in the HLA-DQ region confer susceptibility to idiopathic achalasia. Nat. Genet. 46, 901-904. doi: 10.1038/ng.3029
Goné-Vázquez, I., Barquera, R., Arellano-Prado, F. P., Hernández-Zaragoza, D. I., Escobedo-Ruíz, A., Clayton, S., et al. (2020). Genetic diversity of HLA system in two populations from Nayarit, Mexico: tepic and rural Nayarit. Hum. Immunol. 81, 499-501. doi: 10.1016/j.humimm.2019.06.008

Gonzalez-Galarza, F. F., McCabe, A., Santos, E., Jones, J., Takeshita, L., OrtegaRivera, N. D., et al. (2020). Allele frequency net database (AFND) 2020 update: gold-standard data classification, open access genotype data and new query tools. Nucleic Acids Res. 48, D783-D788. doi: 10.1093/nar/gkz1029

González-Medina, L., Barquera, R., Delgado-Aguirre, H., Clayton, S., Adalid-Sáinz, C., Arrieta-Bolaños, E., et al. (2020). Genetic diversity of HLA system in two populations from Durango, Mexico: Durango city and rural Durango. Hum. Immunol. 81, 489-491. doi: 10.1016/j.humimm.2019.06.005

Gorodezky, C. (2006). "Immunobiology of the Human MHC: vol. 1. International Histocompatibility Workshop and Conference," in Proceedings of the 13th International Histocompatibility Workshop Anthropology/Human Genetic Diversity Joint Report: introduction and overview, ed. J. A. Hansen (Victoria, Ca; Seattle: Int. Histocompatibility Working Group Press).

Gorodezky, C., Najera, R., Rangel, B. E., Castro, L. E., Flores, J., Velázquez, G., et al. (1986). Immunogenetic profile of multiple sclerosis in Mexicans. Hum. Immunol. 16, 364-374. doi: 10.1016/0198-8859(86)90063-7

Graham, R. R., Ortmann, W., Rodine, P., Espe, K., Langefeld, C., Lange, E., et al. (2007). Specific combinations of HLA-DR2, and DR3 class II haplotypes contribute graded risk for disease susceptibility, and autoantibodies in human SLE. Eur. J. Hum. Genet. 15, 823-830.

Granados, J., Vargas-Alarcón, G., Andrade, F., Melín-Aldana, H., Alcocer-Varela, J., and Alarcón-Segovia, D. (1996). The role of HLA-DR alleles and complotypes through the ethnic barrier in systemic lupus erythematosus in Mexicans. Lupus $5,184-189$.

Granados, J., Vargas-Alarcón, G., Drenkard, C., Andrade, F., Melín-Aldana, H., Alcocer-Varela, J., et al. (1997). Relationship of anticardiolipin antibodies and antiphospholipid syndrome to HLA-DR7 in Mexican patients with systemic lupus erythematosus (SLE). Lupus 6, 57-62. doi: 10.1177/096120339700600108

Grimaldi, M. C., Crouau-Roy, B., Amoros, J. P., Cambon-Thomsen, A., Carcassi, C., Orru, S., et al. (2001). West Mediterranean islands (Corsica, Balearic islands, Sardinia) and the Basque population: contribution of HLA class I molecular markers to their evolutionary history. Tissue Antigens 58, 281-292. doi: 10.1034/ j.1399-0039.2001.580501.x

Guo, S. W., and Thompson, E. A. (1992). Performing the exact test of Hardy-Weinberg proportion for multiple alleles. Biometrics 48, 361-372.

Guzmán, J., Cardiel, M. H., Arce-Salinas, A., Sánchez-Guerrero, J., and AlarcónSegovia, D. (1992). Measurement of disease activity in systemic lupus erythematosus. Prospective validation of 3 clinical indices. J. Rheumatol. 19, $1551-1558$

Hernández-Hernández, O., Hernández-Zaragoza, D. I., Barquera, R., Warinner, C., López-Gil, C., Arrieta-Bolaños, E., et al. (2020). Genetic diversity of HLA system in two populations from Oaxaca, Mexico: Oaxaca city and rural Oaxaca. Hum. Immunol. 81, 553-556. doi: 10.1016/j.humimm.2019.07.278

Hernández-Zaragoza, D. I., Rodríguez-Munguía, T. J., Barquera, R., Adalid-Sáinz, C., Arrieta-Bolaños, E., Clayton, S., et al. (2020). Genetic diversity of HLA system in two populations from San Luis Potosí, Mexico: San Luis Potosí City and rural San Luis Potosí. Hum. Immunol. 81, 528-530. doi: 10.1016/j. humimm.2019.07.291

Hochberg, M. C. (1997). Updating the American College of Rheumatology revised criteria for the classification of systemic lupus erythematosus. Arthritis Rheum. 40:1725. doi: 10.1002/art.1780400928

Hollenbach, J. A., Thomson, G., Cao, K., Fernandez-Vina, M., Erlich, H. A., Bugawan, T. L., et al. (2001). HLA diversity, differentiation, and haplotype evolution in Mesoamerican Natives. Hum. Immunol. 62, 378-390. doi: 10.1016/ s0198-8859(01)00212-9

Infante, E., Olivo, A., Alaez, C., Williams, F., Middleton, D., de la Rosa, G., (1999). Molecular analysis of HLA class I alleles in the Mexican Seri Indians: implications for their origin. Tissue Antigens. 54, 35-42. doi: 10.1034/j.13990039.1999.540104.x

Izmirly, P. M., Wan, I., Sahl, S., Buyon, J. P., Belmont, H. M., Salmon, J. E., et al. (2017). The incidence and prevalence of systemic lupus erythematosus in New York County (Manhattan), New York: the manhattan lupus surveillance program. Arthritis Rheumatol. 69, 2006-2017. doi: 10.1002/art.40192 
Juárez-Cedillo, T., Zuñiga, J., Acuña-Alonzo, V., Pérez-Hernández, N., RodríguezPérez, J. M., Barquera, R., et al. (2008). Genetic admixture and diversity estimations in the Mexican Mestizo population from Mexico City using 15 STR polymorphic markers. Forensic. Sci. Int. Genet. 2, e37-e39. doi: 10.1016/j.fsigen. 2007.08.017

Juárez-Nicolás, F., Barquera, R., Martínez-Álvarez, J. C., Hernández-Zaragoza, D. I., Ortega-Yáñez, A., Arrieta-Bolaños, E., et al. (2020). Genetic diversity of HLA system in a population from Guerrero, Mexico. Hum. Immunol. 81, 550-552. doi: 10.1016/j.humimm.2019.05.015

Kijak, G. H., Walsh, A. M., Koehler, R. N., Moqueet, N., Eller, L. A., Eller, M., et al. (2009). HLA class I allele and haplotype diversity in Ugandans supports the presence of a major east African genetic cluster. Tissue Antigens 73, 262-269. doi: 10.1111/j.1399-0039.2008.01192.x

Lebedeva, T. V., Mastromarino, S. A., Lee, E., Ohashi, M., Alosco, S. M., and Yu, N. (2011). Resolution of HLA class I sequence-based typing ambiguities by groupspecific sequencing primers. Tissue Antigens 77, 247-250. doi: 10.1111/j.13990039.2010.01616.x

Louie, L. (2006a). "Immunobiology of the Human MHC: vol. 1. International Histocompatibility Workshop and Conference," in Proceedings of the 13th International Histocompatibility Workshop Anthropology/Human Genetic Diversity Joint Report: introduction and overview, ed. J. A. Hansen (Victoria, Ca; Seattle: Int. Histocompatibility Working Group Press).

Louie L. (2006b). 13th International Histocompatibility Workshop Anthropology/Human Genetic Diversity Joint Report: HLA genetic differentiation of the 13th IHWC Population Data Relative to Worldwide Linguistic Families. Victoria, Ca; Seattle: IHWG Press.

Mack, S. J., Meyer, D., Single, R. M., Sanchez-Mazas, A., Thomson, G., and Erlich, H. A. (2006). "13th International Histocompatibility Workshop Anthropology/Human Genetic Diversity Joint Report: introduction and overview," in Immunobiology of the Human MHC: vol. 1. International Histocompatibility Workshop and Conference, ed. J. A. Hansen (Seattle: Int. Histocompatibility Working Group Press), 560-563.

Magistrelli, C., Samoilova, E., Agarwal, R. K., Banki, K., Ferrante, P., Vladutiu, A., et al. (1999). Polymorphic genotypes of the HRES-1 human endogenous retrovirus locus correlate with systemic lupus erythematosus and autoreactivity. Immunogenetics 49, 829-834. doi: 10.1007/s002510050561

Martínez-Álvarez, J. C., Barquera, R., Hernández-Zaragoza, D. I., Bravo-Acevedo, A., Clayton, S., Arrieta-Bolaños, E., et al. (2020). Genetic diversity of HLA system in two populations from Querétaro, Mexico: querétaro city and rural Querétaro. Hum. Immunol. 81, 522-524. doi: 10.1016/j.humimm.2019.07. 296

Medina-Escobedo, C. E., Barquera, R., Ponnandai-Shanmugavel, K. S., LaraRiegos, J., Bravo-Acevedo, A., Arrieta-Bolaños, E., et al. (2020). Genetic diversity of HLA system in two populations from Quintana Roo, Mexico: cancún and rural Quintana Roo. Hum. Immunol. 81, 573-575.

Middleton, D., Williams, F., Hamill, M. A., and Meenagh, A. (2000). Frequency of HLA-B alleles in a Caucasoid population determined by a two-stage PCR-SSOP typing strategy. Hum. Immunol. 61, 1285-1297. doi: 10.1016/S0198-8859(00) 00186-5

Mišunová, M., Svitálková, T., Pleštilová, L., Kryštufková, O., Tegzová, D., Svobodová, R., et al. (2017). Molecular markers of systemic autoimmune disorders: the expression of MHC-located HSP70 genes is significantly associated with autoimmunity development. Clin. Exp. Rheumatol. 35, 33-42.

Modiano, D., Luoni, G., Petrarca, V., Sodiomon Sirima, B., De Luca, M., Simporé, J., et al. (2001). HLA class I in three West African ethnic groups: genetic distances from sub-Saharan and Caucasoid populations. Tissue Antigens 57, 128-137. doi: 10.1034/j.1399-0039.2001.057002128.x

Mohd-Yusuf, Y., Phipps, M. E., Chow, S. K., and Yeap, S. S. (2011). HLA-A*11, and novel associations in Malays, and Chinese with systemic lupus erythematosus. Immunol. Lett. 139, 68-72.

Molineros, J. E., Looger, L. L., Kim, K., Okada, Y., Terao, C., Sun, C., et al. (2019). Amino acid signatures of HLA Class-I and II molecules are strongly associated with SLE susceptibility and autoantibody production in Eastern Asians. PLoS Genet. 15:e1008092. doi: 10.1371/journal.pgen.1008092

Moreno-Estrada, A., Gignoux, C. R., Fernández-López, J. C., Zakharia, F., Sikora, M., Contreras, A. V., et al. (2014). Human genetics. The genetics of Mexico recapitulates Native American substructure and affects biomedical traits. Science 344, 1280-1285. doi: 10.1126/science. 1251688

Morris, D. L., Taylor, K. E., Fernando, M. M., Nititham, J., Alarcón-Riquelme, M. E., Barcellos, L. F., et al. (2012). Unraveling multiple MHC gene associations with systemic lupus erythematosus: model choice indicates a role for HLA alleles and non-HLA genes in Europeans. Am. J. Hum. Genet. 91, 778-793. doi: 10.1016/j.ajhg.2012.08.026

Norman, P. J., Hollenbach, J. A., Nemat-Gorgani, N., Guethlein, L. A., Hilton, H. G., Pando, M. J., et al. (2013). Co-evolution of human leukocyte antigen (HLA) class I ligands with killer-cell immunoglobulin-like receptors (KIR) in a genetically diverse population of sub-Saharan Africans. PLoS Genet. 9:e1003938. doi: 10.1371/journal.pgen.1003938

Ordoñez, G., Romero, S., Orozco, L., Pineda, B., Jiménez-Morales, S., Nieto, A., et al. (2015). Genomewide admixture study in Mexican Mestizos with multiple sclerosis. Clin. Neurol. Neurosurg. 130, 55-60. doi: 10.1016/j.clineuro.2014.11. 026

Ortega-Yáñez, A., Barquera, R., Curiel-Giles, L., Martínez-Álvarez, J. C., MacíasMedrano, R. M., Arrieta-Bolaños, E., et al. (2020). Genetic diversity of HLA system in two populations from Morelos, Mexico: cuernavaca and rural Morelos. Hum. Immunol. 81, 557-559. doi: 10.1016/j.humimm.2019.07.289

Pacheco-Ubaldo, H., Adalid-Sáinz, C., Barquera, R., Clayton, S., Arrieta-Bolaños, E., Delgado-Aguirre, H., et al. (2020). Genetic diversity of HLA system in three populations from Chihuahua, Mexico: Chihuahua City, Ciudad Juárez and rural Chihuahua. Hum. Immunol. 81, 485-488. doi: 10.1016/j.humimm.2019. 05.014

Pantoja-Torres, J. A., Barquera, R., Ballesteros-Romero, M., Bravo-Acevedo, A., Arrieta-Bolaños, E., Montiel-Hernández, G. D., et al. (2020). Genetic diversity of HLA system in three populations from Guanajuato, Mexico: Guanajuato City, León and rural Guanajuato. Hum. Immunol. 81, 510-512. doi: 10.1016/ j.humimm.2019.06.002

Partanen, J., Koskimies, S., and Johansson, E. (1988). C4 null phenotypes among lupus erythematosus patients are predominantly the result of deletions covering C4 and closely linked 21-hydroxylase A genes. J. Med. Genet. 25, 387-391. doi: 10.1136/jmg.25.6.387

Perl, A., Colombo, E., Dai, H., Agarwal, R., Mark, K. A., Banki, K., et al. (1995). Antibody reactivity to the HRES-1 endogenous retroviral element identifies a subset of patients with systemic lupus erythematosus and overlap syndromes. Correlation with antinuclear antibodies and HLA class II alleles. Arthritis Rheum. 38, 1660-1671. doi: 10.1002/art.1780381119

Picceli, V. F., Skare, T. L., Nisihara, R. M., Nass, F. R., Messias-Reason, I. T., and Utiyama, S. R. (2016). BF* F allotype of the alternative pathway of complement: A marker of protection against the development of antiphospholipid antibodies in patients with systemic lupus erythematosus. Lupus 25, 412-417. doi: 10.1177/ 0961203315615222

Pimtanothai, N., Hurley, C. K., Leke, R., Klitz, W., and Johnson, A. H. (2001). HLA-DR and -DQ polymorphism in Cameroon. Tissue Antigens 58, 1-8. doi: 10.1034/j.1399-0039.2001.580101.x

Quaglia, M., Merlotti, G., De Andrea, M., Borgogna, C., and Cantaluppi, V. (2021). Viral Infections and Systemic Lupus Erythematosus: new players in an old story. Viruses 13:277. doi: 10.3390/v13020277

R Core Team (2020). R: A Language and Environment for Statistical Computing. Vienna: R Foundation for Statistical Computing.

Ramírez-Bello, J., Cadena-Sandoval, D., Mendoza-Rincón, J. F., Barbosa-Cobos, R. E., Sánchez-Muñoz, F., Amezcua-Guerra, L. M., et al. (2018). Tumor necrosis factor gene polymorphisms are associated with systemic lupus erythematosus susceptibility or lupus nephritis in Mexican patients. Immunol. Res. 66, 348354. doi: 10.1007/s12026-018-8993-8

Rees, F., Doherty, M., Grainge, M. J., Lanyon, P., and Zhang, W. (2017). The worldwide incidence and prevalence of systemic lupus erythematosus: a systematic review of epidemiological studies. Rheumatology (Oxford) 56, 1945-1961. doi: 10.1093/rheumatology/kex260

Robinson, J. (2001). IMGT/HLA Database a sequence database for the human major histocompatibility complex. Nucleic Acids Res. 29, 210-213. doi: 10.1093/ nar/29.1.210

Romero-Hidalgo, S., Flores-Rivera, J., Rivas-Alonso, V., Barquera, R., VillarrealMolina, M. T., Antuna-Puente, B., et al. (2020). Native American ancestry significantly contributes to neuromyelitis optica susceptibility in the admixed Mexican population. Sci Rep. 10:13706. doi: 10.1038/s41598-020-69224-3

Salgado-Galicia, N. A., Hernández-Doño, S., Ruiz-Gómez, D., Jakez-Ocampo, J., Zúñiga, J., Vargas-Alarcón, G., et al. (2020). The role of socioeconomic status in the susceptibility to develop systemic lupus erythematosus in Mexican patients. Clin. Rheumatol. 39, 2151-2161. doi: 10.1007/s10067-020-04928-5

Sepúlveda Delgado, J., Lozano Dannis, R., Ocaa-Sibilla, M. J., Ramirez Valdespino, J., Cetina Díaz, J., Bulos Rodríguez, P., et al. (2018). Role of the HLA-DRB1*15 
and HLA-DRB1*16 alleles in the genetic susceptibility to develop systemic lupus erythematosus (SLE) after Chikungunya and Zika viruses infection in Mexico. Blood Genomics 2, 233-236. doi: 10.46701/APJBG.2018042018127

Single, R. M., Meyer, D., Nunes, K., Francisco, R. S., Hünemeier, T., Maiers, M., et al. (2020). Demographic history and selection at HLA loci in Native Americans. PLoS One 15:e0241282. doi: 10.1371/journal.pone.0241282

Solís-Martínez, R., Barquera, R., Ponnandai-Shanmugavel, K. S., Vega-Martínez, M. D. R., Vázquez-Castillo, T. V., Arrieta-Bolaños, E., et al. (2020). Genetic diversity of HLA system in two populations from Tabasco, Mexico: villahermosa and rural Tabasco. Hum. Immunol. 81, 560-562. doi: 10.1016/j. humimm.2019.07.286

Szilágyi, A., Bánlaki, Z., Pozsonyi, E., Yunis, E. J., Awdeh, Z. L., Hossó, A., et al. (2010). Frequent occurrence of conserved extended haplotypes (CEHs) in two Caucasian populations. Mol. Immunol. 47, 1899-1904. doi: 10.1016/j.molimm.2010.03.013

Trachtenberg, E., Vinson, M., Hayes, E., Hsu, Y. M., Houtchens, K., Erlich, H., et al. (2007). HLA class I (A, B, C) and class II (DRB1, DQA1, DQB1, DPB1) alleles and haplotypes in the Han from southern China. Tissue Antigens 70, 455-463. doi: 10.1111/j.1399-0039.2007.00932.x

Tsokos, G. C., Lo, M. S., Costa Reis, P., and Sullivan, K. E. (2016). New insights into the immunopathogenesis of systemic lupus erythematosus. Nat. Rev. Rheumatol. 12, 716-730. doi: 10.1038/nrrheum.2016.186

Uribe-Duarte, M. G., Aguilar-Campos, J. A., Barquera, R., Bravo-Acevedo, A., Clayton, S., Arrieta-Bolaños, E., et al. (2020). Genetic diversity of HLA system in three populations from Sonora, Mexico: ciudad Obregón, Hermosillo and rural Sonora. Hum. Immunol. 81, 478-481. doi: 10.1016/j.humimm.2019.05. 013

Vargas-Alarcón, G., Hernández-Pacheco, G., Zuñiga, J., Rodríguez-Pérez, J. M., Pérez-Hernández, N., Rangel, C., et al. (2003). Distribution of HLA-B alleles in Mexican Amerindian populations. Immunogenetics 54, 756-760. doi: 10.1007/ s00251-002-0522-0

Vargas-Alarcón, G., Salgado, N., Granados, J., Gómez-Casado, E., Martinez-Laso, J., Alcocer-Varela, J., et al. (2001). Class II allele and haplotype frequencies in Mexican systemic lupus erythematosus patients: the relevance of considering homologous chromosomes in determining susceptibility. Hum. Immunol. 62, 814-820. doi: 10.1016/s0198-8859(01)00267-1

Vasconcelos, C., Carvalho, C., Leal, B., Pereira, C., Bettencourt, A., Costa, P. P., et al. (2009). HLA in Portuguese systemic lupus erythematosus patients and their relation to clinical features. Ann. N. Y. Acad. Sci. 1173, 575-580. doi: 10.1111/j.1749-6632.2009.04873.x

Verne, G. N., Hahn, A. B., Pineau, B. C., Hoffman, B. J., Wojciechowski, B. W., and Wu, W. C. (1999). Association of HLA-DR and -DQ alleles with idiopathic achalasia. Gastroenterology 117, 26-31. doi: 10.1016/s0016-5085(99)70546-9
Wang, J. (2003). Maximum-likelihood estimation of admixture proportions from genetic data. Genetics 164, 747-765.

Wescott, M. Z., Awdeh, Z. L., Yunis, E. J., and Alper, C. A. (1987). Molecular analysis distinguishes two HLA-DR3-bearing major histocompatibility complex extended haplotypes. Immunogenetics 26, 370-374. doi: 10.1007/bf00343707

Williams, F., Meenagh, A., Maxwell, A. P., and Middleton, D. (1999). Allele resolution of HLA-A using oligonucleotide probes in a two-stage typing strategy. Tissue Antigens 54, 59-68. doi: 10.1034/j.1399-0039.1999.540107.x

Yunis, E. J., Larsen, C. E., Fernandez-Viña, M., Awdeh, Z. L., Romero, T., Hansen, J. A., et al. (2003). Inheritable variable sizes of DNA stretches in the human MHC: conserved extended haplotypes and their fragments or blocks. Tissue Antigens 62, 1-20. doi: 10.1034/j.1399-0039.2003.00098.x

Yunis, E., Zuniga, J., Larsen, C., Fernandez-Vina, M., and Granados, J. (2005). Single Nucleotide Polymorphism blocks and haplotypes: Human MHC blocks diversity. in Encyclopedia of Molecular Cell Biology and Molecular Medicine, 2nd Edn. Weinheim: Wiley-VCH Verlag GmbH \& Co, 191-215.

Zúñiga, J., Vargas-Alarcón, G., Hernández-Pacheco, G., Portal-Celhay, C., Yamamoto-Furusho, J. K., and Granados, J. (2001). Tumor necrosis factoralpha promoter polymorphisms in Mexican patients with systemic lupus erythematosus (SLE). Genes Immun. 2, 363-366. doi: 10.1038/sj.gene.6363793

Zúñiga, J., Yu, N., Barquera, R., Alosco, S., Ohashi, M., Lebedeva, T., et al. (2013). HLA class I and class II conserved extended haplotypes and their fragments or blocks in Mexicans: implications for the study of genetic diversity in admixed populations. PLoS One 8:e74442. doi: 10.1371/journal.pone.0074442

Conflict of Interest: The authors declare that the research was conducted in the absence of any commercial or financial relationships that could be construed as a potential conflict of interest.

Publisher's Note: All claims expressed in this article are solely those of the authors and do not necessarily represent those of their affiliated organizations, or those of the publisher, the editors and the reviewers. Any product that may be evaluated in this article, or claim that may be made by its manufacturer, is not guaranteed or endorsed by the publisher.

Copyright (C) 2021 Hernández-Doño, Jakez-Ocampo, Márquez-García, Ruiz, AcuñaAlonzo, Lima, Llorente, Tovar-Méndez, García-Silva, Granados, Zúñiga and VargasAlarcón. This is an open-access article distributed under the terms of the Creative Commons Attribution License (CC BY). The use, distribution or reproduction in other forums is permitted, provided the original author(s) and the copyright owner(s) are credited and that the original publication in this journal is cited, in accordance with accepted academic practice. No use, distribution or reproduction is permitted which does not comply with these terms. 